\title{
Early Peripheral Nerve Regeneration after Crushing, Sectioning, and Freeze Studied by Implanted Electrodes in the Cat
}

\author{
K. Fugleholm, H. Schmalbruch, and C. Krarup \\ Institute of Medical Physiology, Panum Institute, University of Copenhagen, and the Department of Clinical \\ Neurophysiology, Rigshospitalet, 2100 Copenhagen, Denmark
}

Regeneration of axons after Wallerian degeneration is influenced by various factors localized to the distal nerve stump. We have examined elongation of axons to assess the relative influence of basal lamina and of Schwann cells in lesions with and without interruption of the Schwann cell tubes. In particular, we wanted to follow the growth of axons throughout the same distal nerve stump. Silicone cuff and patch electrodes with multiple contacts were therefore implanted around hindlimb nerves proximal and distal to the lesion. The tibial nerve was cut and sutured (15 nerves) or crushed (10 nerves). A 20-25-mm-long segment distal to the lesion was in addition frozen in four crushed and in seven sectioned nerves to eliminate the Schwann cells. Six unlesioned tibial nerves from four cats served as control. Reinnervation of plantar muscle occurred 42-54 $\mathrm{d}$ after nerve crushing and 42-84 $\mathrm{d}$ after nerve sectioning $(P<0.01)$. Regeneration was followed by weekly electrophysiological observations that allowed serial identification of the fastestgrowing-individual axons, with conduction velocities of 0.5 $3 \mathrm{~m} / \mathrm{sec}$ and amplitudes of $0.15-0.5 \mu \mathrm{V}$. Unmyelinated axons were present at the most distal lead of the electrode array from which action potentials were identified. The rate of elongation after both crushing and crush + freeze was 3-4 $\mathrm{mm} / \mathrm{d}$, and after sectioning only $2.5 \mathrm{~mm} / \mathrm{d}(P<0.01)$. Freezing in addition to sectioning was associated with even slower elongation of $1.2 \mathrm{~mm} / \mathrm{d}$. Distal to the frozen portion of the nerve elongation accelerated. Our findings suggest that regeneration was slowed throughout the nerve distal to a sectioning compared with a crushing lesion, and that depletion of Schwann cells only influenced axonal elongation after interruption of the basal lamina. This suggests that the basal lamina tubes at the lesion site may facilitate the action of neurotropic factors of distal origin.

\footnotetext{
Received Apr. 5, 1993; revised Oct. 7, 1993; accepted Oct. 19, 1993.

We are grateful to Dr. D. M. Lewis for comments on the manuscript and to Mrs. Lis Hansen and Susanne Sørensen for expert technical assistance. The study was supported by the Muscular Dystrophy Association (USA), the National Institutes of Health (R29NS25688), the Danish Medical Research Council (12-9680, 12-0293), the Lundbeck Foundation, the Novo Foundation, the Foundation for Neurological Research, the Danish Hospital Foundation for Medical Research (Region of Copenhagen, the Faroe Islands and Greenland), the Henry Hansen and wife Karla Hansen, born Westergaard Foundation, the Ib Henriksen Foundation, the P. A. Messerschmidt and wife Foundation, and the Danish Medical Association.

Correspondence should be addressed to Christian Krarup, Department of Clinical Neurophysiology, Rigshospitalet, 9 Blegdamsvej, 2100 Copenhagen, Denmark.

Copyright (C) 1994 Society for Neuroscience $0270-6474 / 94 / 142659-15 \$ 05.00 / 0$
}

IKey words: peripheral nerve, regeneration, Schwann cells, implanted electrodes, electrophysiology, electron microscopy I

Several lines of evidence suggest that the distal nerve stump has important tropic effects on axons regenerating after Wallerian degeneration. It has been shown in different species that nerve fibers preferentially grow toward a peripheral nerve stump (Lundborg et al., 1986; Mackinnon et al., 1986; Weis and Schröder, 1989). This directional growth may be due to a tropic effect exerted by chemotactic diffusible factors (Politis et al., 1982). On the other hand, the preferential reinnervation of a motor nerve by motor neurons (Brushart, 1988) was suggested to be due to trophic interactions between the axons and the pathway or the end-organ (Brushart, 1990). Other studies suggest that surface factors associated with the basal lamina may be equally or even more important for early axonal elongation than diffusible factors (Ard et al., 1987; Bresjanac and Sketelj, 1989).

In order to study the relative importance of such factors on regeneration in vivo, it is important to be able to follow the outgrowth of fibers in the same nerve, and to be able to ascertain whether changes in rate of elongation along the innervation path occur as a consequence of different lesion procedures. Most electrophysiological studies of peripheral nerve regeneration in vivo have, however, been carried out by recording the compound action potential from muscle supplied by the lesioned nerve (Hodes et al., 1948; Gilliatt and Hjorth, 1972; Williams and Gilliatt, 1977; Krarup and Gilliatt, 1985). This approach does not uncover transient changes in the rate of outgrowth. In vitro measurements of conduction along segments of nerves regenerated after different types of lesions have been of use in determining the most distal site reached during regeneration at a given point in time (Berry et al., 1944; Jacobson and Guth, 1965). However, as these recordings do not allow sequential observations from the same nerve fiber population during regeneration, statistical evaluation of large groups of nerves is necessary to demonstrate variations in outgrowth of axons after different lesions. Histological studies have the same disadvantage.

We have therefore used a method of implanting arrays of electrodes along the nerve in order to follow the axons as they grow along the distal nerve stump after Wallerian degeneration. Stcin et al. (1975) used implanted cuff electrodes around cat nerves to record nerve action potentials over long periods, and Davis et al. (1978) examined retrograde changes after a distal nerve lesion. Krarup et al. (1988) used the same method to 


\begin{tabular}{lll}
\hline Table 1. & Tibial nerve lesions & \\
Cat & Right & Left \\
\hline $4^{a}$ & Crush & Crush + freeze \\
6 & Crush $^{b}$ & Section \\
7 & Section & Section + freeze \\
2 & No lesion & Section \\
2 & No lesion & No lesion
\end{tabular}

${ }^{a}$ One cat had no implanted electrodes.

${ }^{h}$ One of the lesions was incomplete and not evaluated in the present study.

follow axonal growth after a crush lesion and found that the method probably could be used to identify the fastest growing fibers. It is possible with this proccdure to record extraccllular action potentials of single axons by averaging (Rindos et al., 1984; Krarup and Loeb, 1988). However, correspondence between the presence of action potentials from a distal electrode site and the presence of nerve fibers and their characteristics has not been ascertained morphologically. We have, by light and electron microscopy, further examined whether the implanted electrodes give an accurate indication of the early growth of nerve fibers and used the method to investigate regeneration after different types of nerve lesions.

Previous studies have shown that regeneration may occur in the absence of Schwann cells both after crushing (Bresjanac and Sketelj, 1989) and sectioning (Ide et al., 1983). The relative influence of the presence of Schwann cells in these situations is, however, unclear. In the cat tibial nerve the rate of axonal elongation and early maturation was determined in conditions with preserved and interrupted Büngner bands (crush vs section lesion) and also after segmental Schwann cell depletion (by freezing and thawing).

A preliminary report has been published (Fugleholm and Krarup, 1992).

\section{Materials and Methods}

\section{Animals}

Twenty-one young adult cats were used. Permission was obtained from the national animal experiment committee.

\section{Narcosis, surgery, and postoperative care}

Deep anesthesia for surgery was induced by intraperitoneal pentobarbital $(40 \mathrm{mg} / \mathrm{kg}$ body weight) and maintained by diluted intravenous doses of pentobarbital $(2.5-5 \mathrm{mg} / \mathrm{kg}$ as required). The hindlimbs and the back were shaved, and the skin disinfected by iodine. During the operation the cat was fixed by hip-pins and rested on a water-heated rubber pad (model K-20, American Medical Systems, Cincinnati, OH) to avoid hypothermia. Tibial nerve lesions and the implantation of electrodes (see below) were performed during the same surgical session under aseptic conditions. The tibial nerve was identified medial to the Achilles tendon and $7 \mathrm{~cm}$ of the nerve, which at this portion is free of branches, was completely freed from surrounding tissue attachments by carcful dissection. After nerve lesions and placement of devices, surgical wounds were closed in at least two layers. The cats were kept in an incubator for up to $3 \mathrm{~d}$ postoperatively to avoid hypothermia. Prophylactic Streptocillin (NOVO, Copenhagen, Denmark; $1.5 \mathrm{ml}, 250 \mathrm{mg}$ of dihydrostreptomycinsulfate and 200,000 IU benzylpenicillinprokain per $\mathrm{ml}$ ) was given intramuscularly preoperatively and for $7 \mathrm{~d}$ postoperatively. The cats were transferred from the incubator to separate cages when fully awake $(2-3 \mathrm{~d})$ and thereafter to a large $(3.5 \times 5.5 \mathrm{~m})$ common cage (after 3-4 d) where they were allowed to move freely. The cats resumed normal locomotion and behavioral pattern 3-4 d after surgery and were carefully observed for gait disturbances, sores, and other signs of discomfort due to the implanted electrodes or the circuit board. When such problems occurred (three cats), the experiment was discontinued.
During the weekly recording sessions the cats were lightly anesthetized with intramuscular ketamine $(15 \mathrm{mg} / \mathrm{kg})$ and xylazine $(2 \mathrm{mg} / \mathrm{kg})$, repeated subcutaneously as necessary. After the sessions the cats were kept for $24 \mathrm{hr}$ in separate cages.

At the completion of the experiment, deep anesthesia for vascular perfusion was induced by intraperitoneal pentobarbital $(40 \mathrm{mg} / \mathrm{kg}$ body weight) and an overdose of $250 \mathrm{mg}$ of pentobarbital was given intracardially at the start of infusion of the fixative (see below).

\section{Nerve lesions}

Lesions were carried out on 36 tibial nerves of 19 cats; six nerves without lesions from four cats were used as controls. Table 1 shows the type of tibial nerve lesion in each leg of the 21 cats studied.

The tibial nerve was crushed or sectioned $1-10 \mathrm{~mm}$ proximal to the tibial cuff electrode (Fig. 1; see below). Crush lesions were made by forceps with 3-mm-wide tips covered with silicone rubber to avoid cutting the supporting connective tissue. The forceps were held clamped for at least $15 \mathrm{sec}$, after which the crushed part of the nerve appeared as a flattened translucent band. The nerves were sectioned with a pair of sharp scissors; the nerve ends were joined using epineural 10-0 nylon suture under an operating microscope. Some nerves were frozen immediately before crushing or sectioning. The frozen segment comprised the lesion site and a distance of $20-25 \mathrm{~mm}$ of the nerve distal to it; that is, the tibial nerve cuff electrode covered approximately $20 \mathrm{~mm}$ of the frozen portion of the nerve. The nerve was lifted from the underlying tissue and a metal probe cooled in liquid nitrogen was intermittently held against it for $5 \mathrm{~min}$ to achieve the effect of repeated freezing and thawing. The effectiveness of this procedure with respect to Schwann cell depletion and axonal degeneration had previously been ensured in two rat sciatic nerves that were studied by electron microscopy after 24 and $48 \mathrm{hr}$ (K. Fugleholm, H. Schmalbruch, and C. Krarup, unpublished observations). Complete loss of axonal continuity was assured electrophysiologically the day after surgery by absence of conduction across the site of the lesion.

\section{Electrophysiology}

Electrodes. In 20 of the 21 cats electrodes were implanted in both hindlimbs around the sciatic and tibial nerves (Fig. 1). Silicone cuff electrodes (Micro Probe Inc., Clarksburg, MD) (Fig. 1) contained multiple circumferentially $\left(270^{\circ}\right.$ of a circle) arranged stainless steel wire electrodes (type 316 alloy, nine strands of $25 \mu \mathrm{m}$, AS 631, Cooner Sales Co., Chatsworth, CA). The electrode placed around the tibial nerve had an internal diameter of $3 \mathrm{~mm}$ and eight leads, and the cuff around the sciatic nerve had an internal diameter of $4 \mathrm{~mm}$ and six leads. After placement, the cuffs were closed by external sutures corresponding to each lead (Fig. 1). The internal diameters of the cuffs were $30-40 \%$ larger than the diameter of the nerves to avoid compression. Free sliding of the nerve within the cuff was ascertained and the cuff was then fixed to underlying muscle fascia. A silicone patch electrode (Fig. 1) with two leads was placed on the fascia of the plantaris muscle and attached by sutures. One wire electrode was implanted subcutaneously on the dorsum of the foot for recording from the plantar flexor muscles. An earth electrode was implanted subcutaneously in the left hip region. All cables were insulated with Teflon except for the bared parts at the stimulation/ recording sites. The leads were passed subcutaneously to the back, resurfaced through a small skin incision, and soldered on connections on a printed circuit board anchored to the spine. The circuit board allowed each lead to be connected for stimulation or recording as needed. Subcutaneous loops of wire were formed in the hip regions to avoid pulling on the nerve during the cat's movements.

Recording sessions. Serial observations began the day after the operation and were repeated weekly. The cat was placed on a water-heated rubber pad $\left(38^{\circ} \mathrm{C}\right)$ and covered with cotton during the recording in order to keep the temperature of the legs and feet reasonably constant. The skin temperature of the foot was measured by means of a thermocouple; it was $33.5-35.5^{\circ} \mathrm{C}$. The electrical integrity of the contacts was tested in situ before each session by measuring the impedances (typically about $500 \Omega$ ) between each lead and earth and between adjacent leads.

Regenerated axons distal to the site of the lesion were identified by stimulating the nerve at the electrode sites in the tibial cuff, and the ascending action potential was recorded at two sites along the undamaged sciatic nerve (Fig. 1, top). The stimulus was first applied to the most proximal pair of the tibial electrodes (cathode at lead 7 , lead numbering as indicated in Fig. 1), and if an action potential could be 


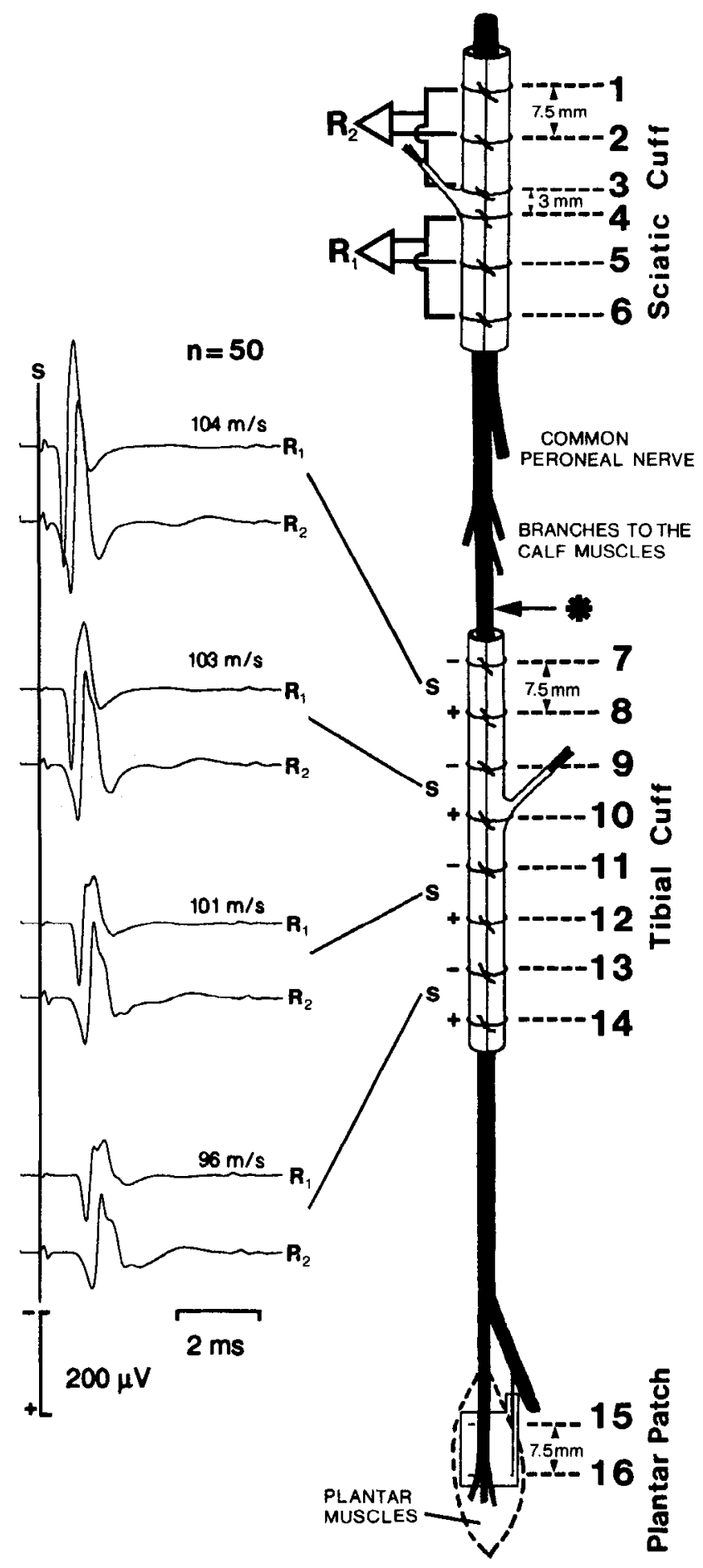

Figure 1. Schematic representation of implanted electrodes. Right, Cuff and patch electrodes at the sciatic, tibial, and plantar nerves. The horizontal dashed lines to the right mark the position of the numbered individual circumferential leads within the cuffs and horizontal leads on the plantar patch. The distances between leads were $7.5 \mathrm{~mm}$, except for $3 \mathrm{~mm}$ between leads 3 and 4 of the sciatic cuff. *, Approximate position of the section or crush lesion. Left, Pairs of ascending compound nerve action potentials from an unlesioned nerve. The responses were evoked at four different sites in the tibial cuff and recorded at two sites along the sciatic nerve. The recording leads were connected in a tripolar configuration $\left(R_{1}\right.$ and $\left.R_{2}\right)$ with a central lead connected to the negative input of the differential amplifier and symmetrically flanked by two shunted leads connected to the positive input. $S$ indicates the onset of the stimulus. The conduction velocity above each pair of traces was calculated from the stimulus cathode to the distal recording site elicited, the stimulus site was stepwise moved in the distal direction (cathode at lead 8,9 , etc.) until an action potential (500 responses averaged with a stimulus repetition rate of 2 per second) was no longer recordable. When the front of regenerating nerve fibers had passed through the tibial cuff, the time needed to reach the plantar muscles and establish functional neuromuscular transmission was determined by recording the muscle action potential from the plantar flexor muscles evoked by stimulation of the tibial nerve. The electrophysiological observations were continued beyond the end-point of the present study in 12 cats in order to follow maturation.

Stimulation. The nerve was activated by a biphasic negative-positive pulse (usually with a duration of each phase of $0.1 \mathrm{msec}$ ) from a photoisolated battery-powered, constant-current stimulator with an output of up to $10 \mathrm{~mA}$. The threshold of normal fibers when stimulated in the tibial or sciatic cuffs was between 0.1 and $0.4 \mathrm{~mA}$. Because of the high threshold of newly regenerated axons $(4-7 \mathrm{~mA})$ it was necessary to apply a stimulus of 7-10 mA (i.e., a 10-20-fold higher maximal stimulus current than in normal nerve) and in some cases to increase the stimulus duration from $0.1 \mathrm{msec}$ to $0.2 \mathrm{msec}$. In most instances the amplitude of the response did not increase further when the stimulus duration was increased. In some instances, however, components were recruited at longer stimulus duration. This occurred together with a shortening of the latency, which made it likely that spread of the stimulus current had occurred.

Recording. Tripolar electrode configurations (Fig. 1, top) were used for recording the nerve action potentials in order to improve spatial focusing (Stein and Pearson, 1971; Stein et al., 1975). The central lead in the tripole (lead number 2 or 5 , Fig. 1) was connected to the negative input and the two flanking leads (lead numbers 1 and 3 or 4 and 6, Fig. 1), at symmetrical distances of $7.5 \mathrm{~mm}$ from the central lead, were connected together to the positive input of the high-impedance differential amplifier (type 15C02, Dantec), with a bandwidth of 200-6000 $\mathrm{Hz}, 3 \mathrm{~dB}$ down. Action potentials were averaged in a Nicolet 4562 averager at sampling intervals of 5-10 $\mu \mathrm{sec}$; responses from single myelinated fibers could be distinguished from noise when 500 responses were averaged (see below).

The compound muscle action potential from the plantar muscles was recorded $(15 \mathrm{C} 02$, Dantec, $10 \mathrm{~Hz}$ to $10 \mathrm{kHz}, 3 \mathrm{~dB}$ down) between one of the leads in the plantar patch and the single wire electrode on the dorsum of the foot, or in some instances between the two electrodes in the plantar patch.

Parameters. The amplitudes of the nerve action potentials were measured peak-to-peak. Latencies were measured to the first positive peak of the response in order to calculate the conduction velocity of the fastest conducting fibers. The conduction velocity along the sciatic nerve was calculated from the distance and conduction time between the central leads of the two sciatic recording tripoles when the tibial nerve was stimulated at one site. The conduction velocity from the tibial to the sciatic nerve was calculated from the stimulus-response latency to the central lead of the most distal sciatic nerve recording tripole. The conduction velocity between two stimulus cathodes along the tibial nerve (along regenerated fibers) was calculated from the distance between them and the difference in latency to one sciatic recording site. Since the same fibers may not be stimulated at two sites along the tibial nerve during carly regeneration, the conduction velocity of the regenerated part of the nerve, that is, between the cathode in the tibial cuff and the lesion site, was also extrapolated in the following way: The conduction time from the lesion to a recording site at the sciatic nerve was calculated from the conduction velocity between the two recording sites in the sciatic nerve. This time was subtracted from the stimulus-response latency between the tibial cathode and the distal sciatic recording site. The resulting conduction time between the tibial cathode and the lesion was finally divided into the distance between stimulus site and lesion. This extrapolation was an average of conduction velocity along a portion of the nerve with varying degree of maturation. Moreover, it did not take into account slow conduction through the site of the nerve lesion

$\left(R_{t}\right)$ and shows a proximodistal conduction velocity gradient. The conduction velocity along the sciatic nerve calculated from the conduction time between $R_{I}$ and $R_{2}$ was $100 \mathrm{~m} / \mathrm{sec}$ for all stimulus sites, and the velocity between two sites of stimulation (cathodes 7 and 13) at the tibial nerve was $85 \mathrm{~m} / \mathrm{sec}$. 

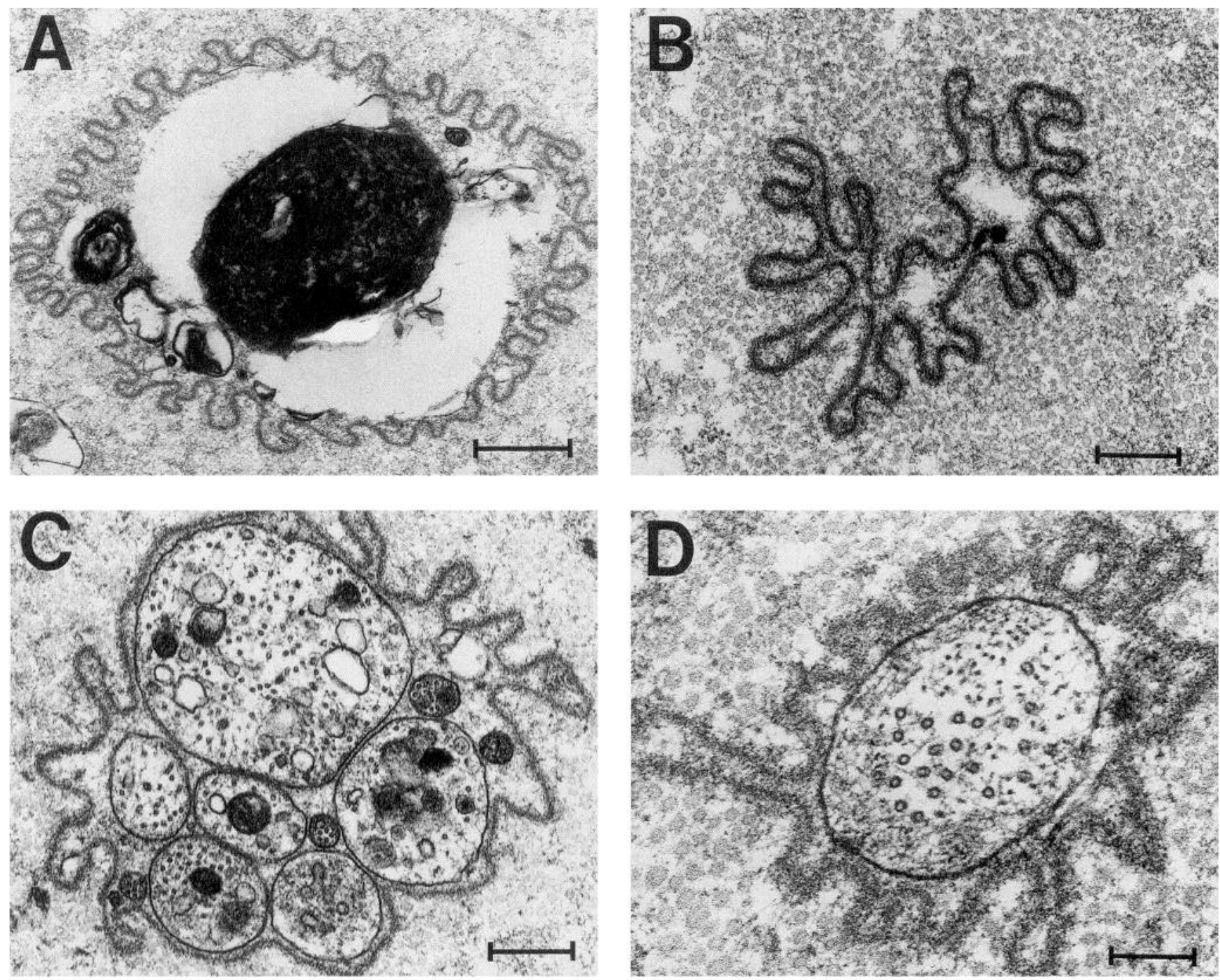

Figure 2. Electron micrographs from a tibial nerve with a crush + freeze injury to show loss of Schwann cells after freezing. The section was obtained $7 \mathrm{~d}$ after the nerve lesion from the frozen nerve segment approximately $5 \mathrm{~mm}$ distal to the crush lesion. $A$, Folded basal lamina tube with myelin debris. From the circumference of the basal lamina profile, the approximate original diameter of the fiber was calculated to $9.4 \mu \mathrm{m}$. $B$, Empty "ghost" basal lamina tube surrounded by collagen fibers. The calculated original diameter was $4.9 \mu \mathrm{m}$. $C$, Basal lamina tube containing several regenerating axonal profiles, but no Schwann cells. The calculated original diameter was $4.4 \mu \mathrm{m}$. $D$, Single axonal profile inside a basal lamina tube. The calculated original diameter was $1.8 \mu \mathrm{m}$. Scale bars: $A, 1 \mu \mathrm{m} ; B$ and $C, 0.5 \mu \mathrm{m} ; D, 0.2 \mu \mathrm{m}$.

and along a portion of the nerve with a variable length (about $1-2 \mathrm{~mm}$ ) of retrograde degeneration and regeneration.

The distances between implanted cuff and patch electrodes were measured after vascular perfusion fixation for histology in a position corresponding to that during recording, that is, $90^{\circ}$ hip and knee flexion and $90^{\circ}$ ankle dorsiflexion. The sciatic, tibial, and plantar nerves were exposed, and all distances, including that to the lesion site, were measured using a piece of wet braided silk suture.

\section{Histological examination}

Five of the 21 cats were terminated before reinnervation of the plantar muscles had occurred. In four of these cats, the tibial nerves were fixed by perfusion via the abdominal aorta with $2.5 \%$ glutaraldehyde in Ringer's solution; the excised nerves were additionally fixed in glutaraldehyde for $15 \mathrm{hr}$, postfixed in $1 \%$ osmium tetroxide, and embedded in Embed 812 (Electron Microscopic Sciences, Fort Washington, PA). One of these cats (right side crushing, left side sectioning) was perfused 2 weeks after surgery immediately after electrophysiological testing; at this time action potentials could be elicited in both legs from electrodes in the tibial cuff(Fig. 1). In order to ascertain the effectiveness of crushing and freezing of the nerve, the tibial nerves of the fifth cat were crushed and crushed and frozen, respectively; no electrodes were implanted. This cat was killed $7 \mathrm{~d}$ after surgery by an overdose of pentobarbital. The tibial nerves were excised without perfusion but otherwise treated as above.

Cross sections of the nerves $3 \mu \mathrm{m}$ thick from various levels of the tibial and plantar nerves were stained with $p$-phenylenediamine. The sections for electron microscopy were stained with uranyl acetate and lead citrate.

The nerves of the cat, which had been terminated when axons had apparently reached the tibial cuff, were investigated by electron microscopy at levels corresponding to the electrodes. The aim of this experiment was to determine whether the most distal site from which an action potential could be elicited would correspond to the front of the outgrowing axons. Approximately $20 \%$ of the total cross-sectional area was screened to identify axonal profiles. The criteria used to distinguish axonal sprouts from Schwann cell processes were that axonal profiles are circular and embedded into Schwann cells, thereby forming mesaxons; that axoplasm always contains prominent microtubules and appears less electron dense than Schwann cell cytoplasm; and that the limiting membrane of an axon has higher contrast than that of a Schwann cell (Toft et al., 1988). The distinctive features were the shape of the axon and the presence of a mesaxon, and there was usually no doubt 
about the nature of a structure even if other criteria were lacking. Axons regenerating through the Schwann cell depleted frozen segment of the nerve might lack accompanying Schwann cells; these axons were identified by their circular profile, the presence of microtubules, the lack of a closely applied basal lamina, and the fact that they were not attached to the persisting basal lamina tube through which they regenerated. The degenerated nerve just distal to the level of unequivocally identifiable axonal sprouts contained a few small circular profiles with microtubules (see below). These profiles were embedded in shallow grooves of Schwann cells but did not form mesaxons; whether they were tips of regenerating axons or thin Schwann cell projections remained obscure.

\section{Results}

At electrophysiological testing 1 week after surgery, neural activity was absent distal to the nerve lesions. This indicated that Wallerian degeneration was complete. Moreover, a nerve that had been crushed and frozen was investigated after 1 week by electron microscopy (Fig. 2) at a site $5 \mathrm{~mm}$ distal to the lesion, and did not contain axons that had survived the injury. The nerve contained myelin debris and many empty ("ghost") basal lamina tubes, some of which contained axonal sprouts without accompanying Schwann cells. This indicated that axotomy was complete and that Schwann cells had been killed by the freezethaw procedure.

\section{Action potentials and histological features during early regeneration}

Stimulation at different levels of the normal tibial nerve and recording from two sites at the sciatic nerve resulted in pairs of similarly shaped compound action potentials with an initial positive phase and amplitudes of 100-500 $\mu \mathrm{V}$. Latency differences of $0.15-0.20 \mathrm{msec}$ between the potentials in each pair corresponded to a conduction velocity of the fastest-conducting fibers in the proximal nerve of $90-120 \mathrm{~m} / \mathrm{sec}$. The conduction velocity between sites of stimulation along the unlesioned tibial nerve was $70-110 \mathrm{~m} / \mathrm{sec}$ (Fig. 1).

When the tibial nerve was stimulated during early regeneration, the amplitudes of the potentials $(0.15-0.50 \mu \mathrm{V})$ at the sciatic nerve were in the range of noise. The smallest potentials that could be distinguished from noise had an amplitude of 0.15 $\mu \mathrm{V}$ and a conduction velocity of $40 \mathrm{~m} / \mathrm{sec}$. Random fast transients with such amplitudes may be recorded, even when 250 500 responses are averaged. The following criteria were used to identify stimulus-elicited potentials as originating from regenerating axons. (1) Action potentials recorded at the two sites along the sciatic nerve had similar configurations with a shift in latency corresponding to the range of conduction velocities of $40-120 \mathrm{~m} / \mathrm{sec}$ of single myelinated nerve fibers of cat examined by similar electrodes (Rindos et al., 1984). (2) The response components were reproducible when 250 and 500 responses were averaged (Fig. 3).

Results obtained in the same cat $16 \mathrm{~d}$ after crushing of the right and sectioning of the left tibial nerve are shown in Figure $4, A$ and $B$, respectively. When the site of stimulation was moved stepwise along the nerve, action potentials with increasing latencies were recorded. The latency of proximally recorded action potentials after stimulation at different distal sites corresponded to conduction velocities of $0.8-8.9 \mathrm{~m} / \mathrm{sec}$ along the immature part of the fibers. The most distal electrode from which a response could be clicited was $47.5 \mathrm{~mm}$ away from the lesion after crushing (Fig. $4 A$ ), and it was $22 \mathrm{~mm}$ away from the lesion after sectioning (Fig. $4 B$ ). The proximal segment of the regenerated nerve contained thinly myelinated axons; only unmyelinated

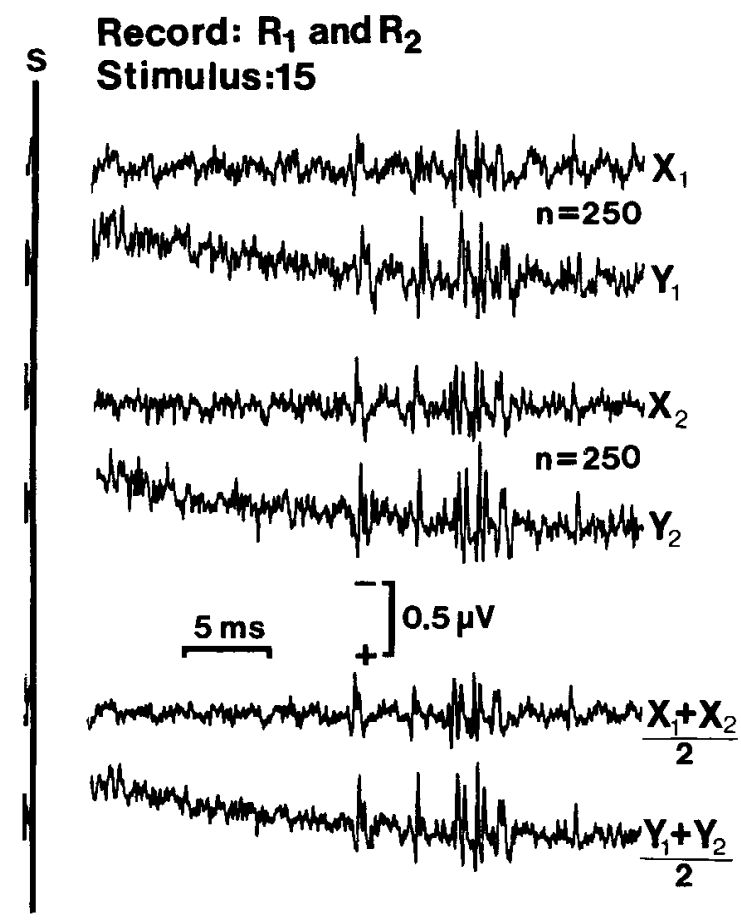

Figure 3. Averaged nerve action potentials to show reproducibility of small-amplitude responses during regeneration 6 weeks after a crush + freeze lesion. The responses were evoked at the plantar patch (cathode 15; see Fig. 1) and recorded from two sites $\left(R_{1}=X\right.$ and $R_{2}=$ $Y)$ along the sciatic nerve. The averages of two independent bins $(X$, and $Y_{t}, X_{2}$ and $Y_{2}$ ) of each 250 sweeps are shown in the upper four traces, and the subsequent average $\left(X_{1}+X_{2} / 2\right.$ and $\left.Y_{1}+Y_{2} / 2\right)$ in the lower two traces. The constant configuration of spikes indicates that the nerve action potentials were time-locked to the stimulus. $S$ indicates the onset of the stimulus. The conduction velocity along the sciatic nerve of the component with shortest latency was $69 \mathrm{~m} / \mathrm{sec}$. Note reduction of noise amplitude in the lower two traces.

axons were found at the site of the most distal electrode from which an action potential could be elicited (Fig. $5 A, B$ ). The distance between this electrode and the more proximal site, where myelin sheaths were histologically detectable, was about $20 \mathrm{~mm}$ after both crush and section lesions (Fig. 4). This suggests that the unmyelinated segments of regenerating myelinated fibers were at least $20 \mathrm{~mm}$ long. The part of the nonresponsive nerve segment just distal to the most distal cathode from which action potentials could be elicited contained myelin sheaths without axons, proliferating Schwann cells, and small cellular processes that could not with certainty be identified, but which might be the tips of new axons (Fig. 5D). Myelin breakdown showed a proximodistal gradient, and some distal myelin sheaths were surprisingly well maintained although they did not contain axons (Fig. 5C). The correlation of electrophysiological and histological findings supports the notion that action potentials could be elicited in the unmyelinated part of regenerating myelinated fibers (Feasby et al., 1981; Krarup et al., 1988).

The nerve action potential of early regenerating nerve fibers consisted of polyphasic responses (Fig. $4 A, B$ ). Its single components were often triphasic; the duration was less than $1 \mathrm{msec}$, and the amplitude was $0.15-0.30 \mu \mathrm{V}$ (Fig. 3). These triphasic responses resembled action potentials from single fibers (Rindos et al., 1984; Krarup and Loeb, 1988). The response originating from the most distal excitable site at the front of the regenerating fiber population sometimes consisted of only a few discrete 

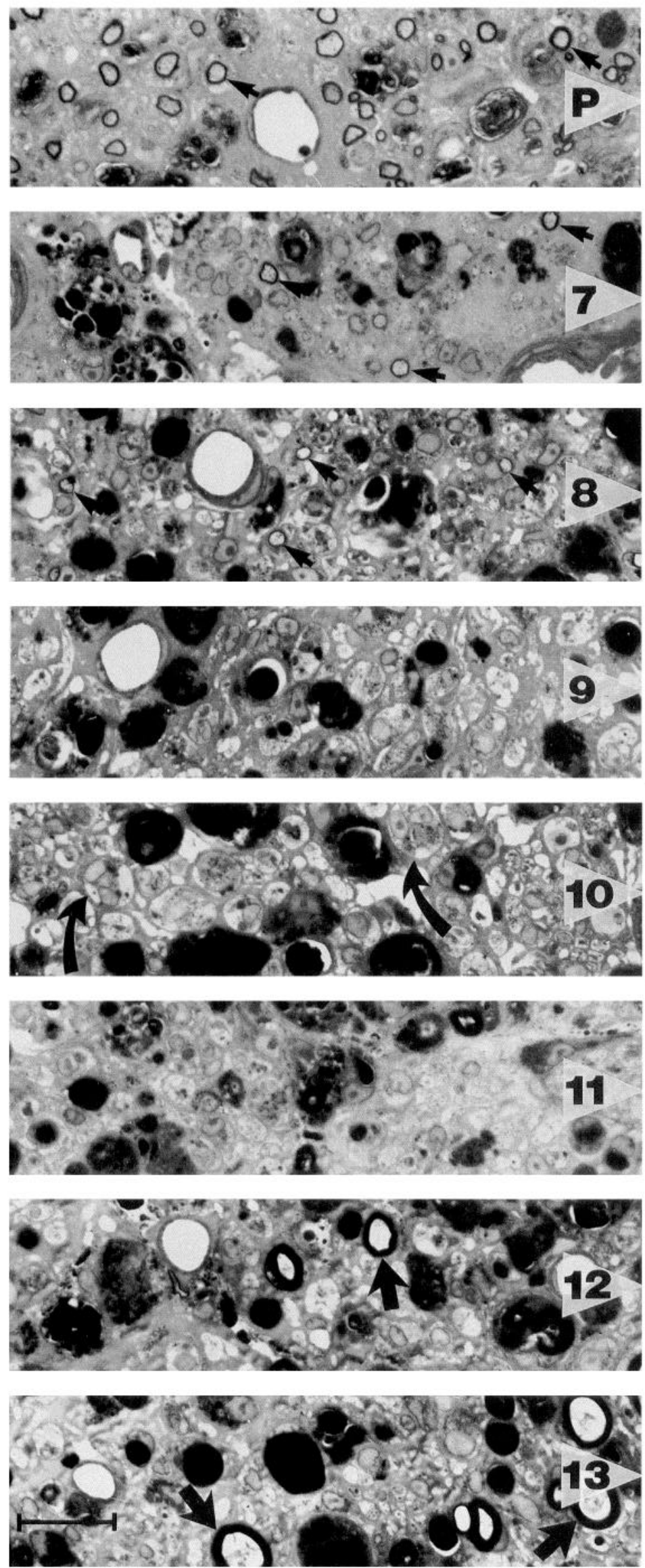

(A) CRUSh

Record: $R_{1}$
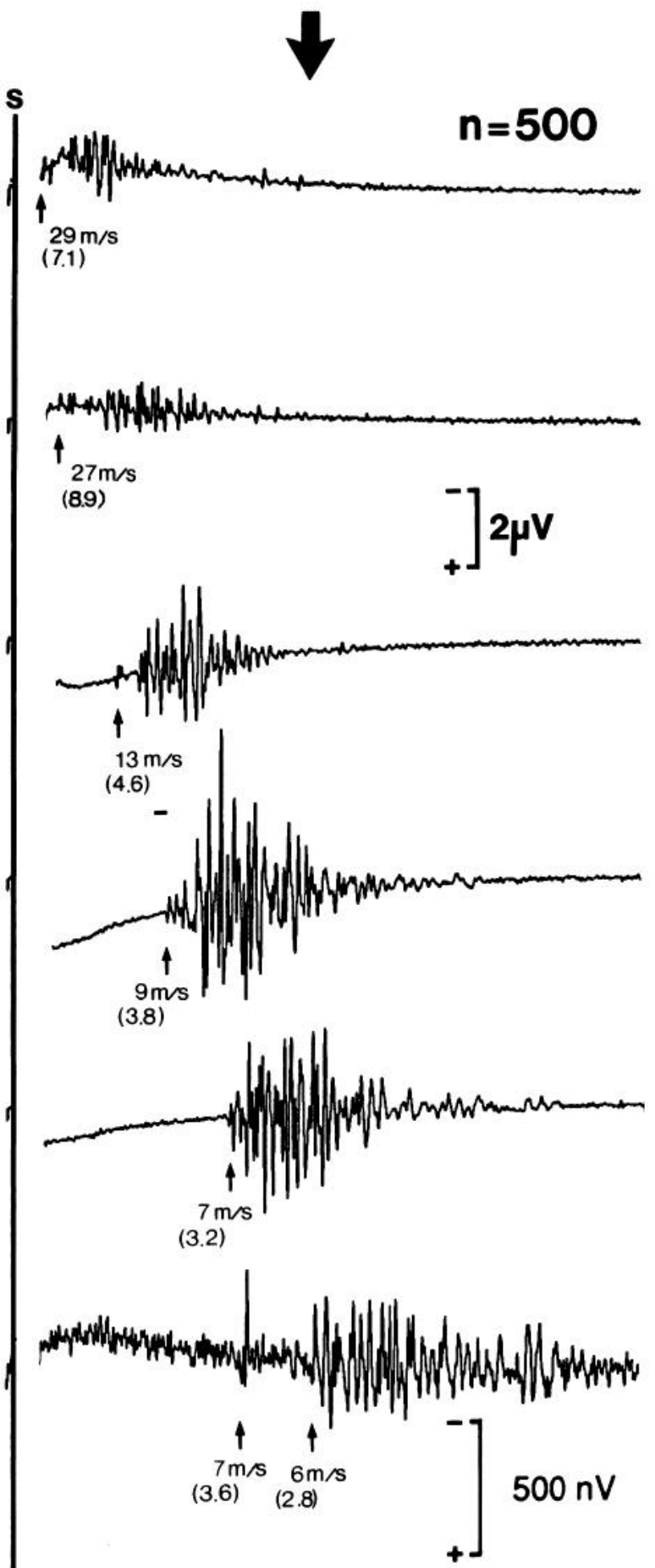

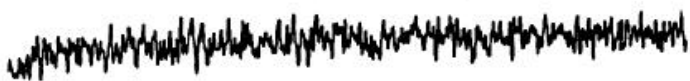

$10 \mathrm{~ms}$ 

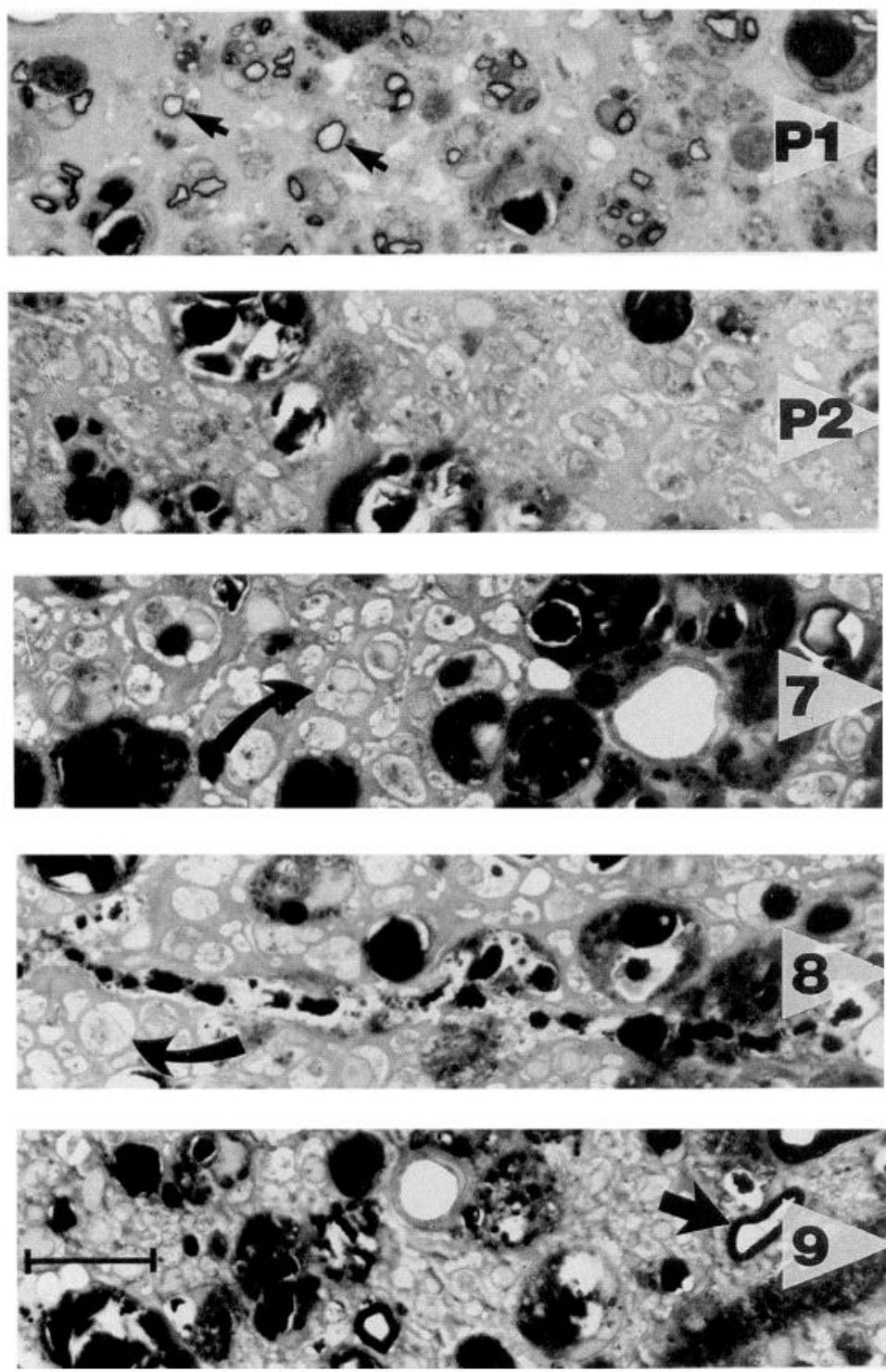

\section{(B) SECTION}

\author{
Record: $R_{1}$
}
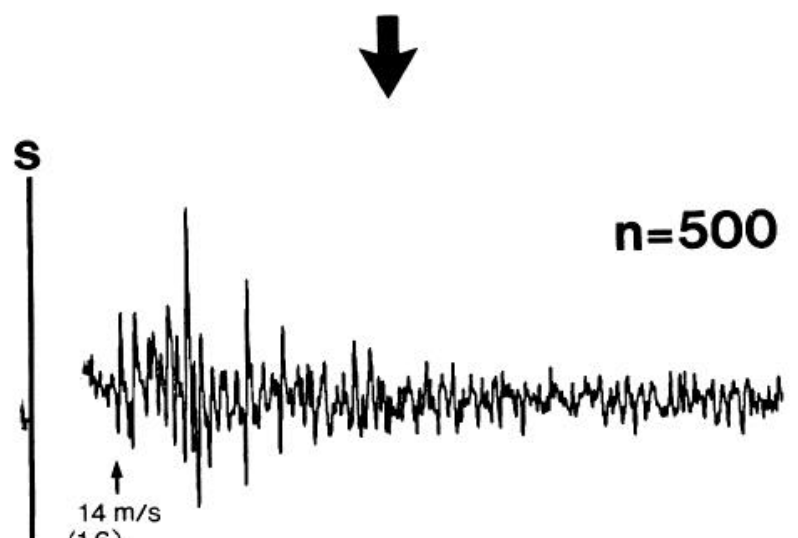

(1.6)

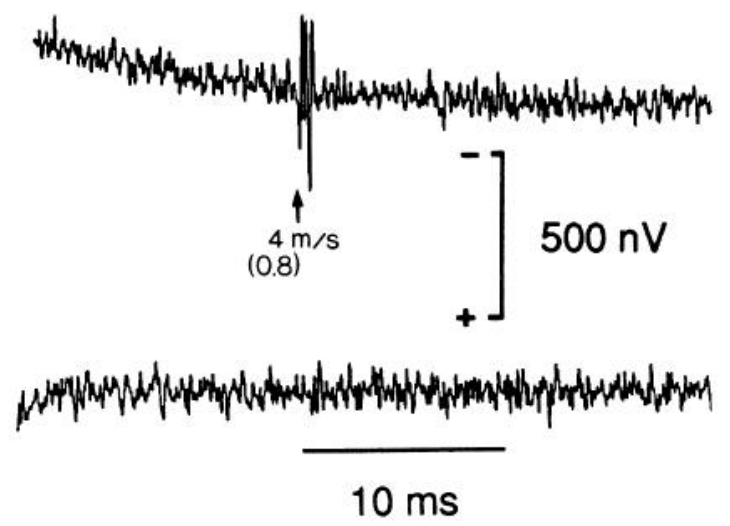

Figure 4. Comparison of histological and electrophysiological evidence of distance of regeneration after nerve crushing $(A)$ and nerve sectioning $(B)$. Left $(A$ and $B)$, Spaced transverse sections of the tibial nerves 16 days after the nerve lesions. The distance between each section was $7.5 \mathrm{~mm}$, and the number at the right in each section indicates the cathode level (see Fig. 1). Right, One hour prior to fixation for histology action potentials were elicited ( $S=$ onset of stimulus) at cathodes corresponding to the transverse sections and recorded at the sciatic nerve $(R$, tripole, $n=$ number averaged). The conduction velocity between the stimulus and recording site is indicated at the arrow. The conduction velocity extrapolated (see Materials and Methods) for the regenerated segment is shown in parentheses. A:Left, The top micrograph $(P)$ was taken $7.5 \mathrm{~mm}$ above the most proximal cathode (7). At more proximal levels fibers were more normally myelinated. The sections show gradients of regeneration and degeneration with small thinly myelinated regenerating fibers (small straight arrows) at levels $\mathrm{P}, 7$, and 8; bands of Büngner (curved arrows) and debris at levels 9-13; and nearly intact but empty myelin sheaths (large straight arrows) at levels 12 and 13. A:Right, action potentials could be elicited from cathodes $7-12$ but not from 13. B:Left, The top two micrographs $(P 1$ and $P 2)$ were taken 15 and 7.5 mm proximal to cathode 7 . The sections show gradients of regeneration and degeneration with small thinly myelinated regenerating fibers (small straight arrows) at level P1; bands of Büngner (curved arrows) and debris at levels P2-9; and nearly intact but empty myelin sheaths (large straight arrows) at level 9. B:Right, Action potentials could be elicited from cathodes 7 and 8 but not from 9 . Scale bars, $20 \mu \mathrm{m}$.

potentials. In order to ascertain whether they originated from single unmyelinated axonal processes of myelinated fibers, it was attempted to show whether they exhibited all-or-nothing behavior. An all-or-nothing response could not be determined at threshold because 250-500 responses had to be averaged. The extracellular action potential from a single fiber would, however, within the range of noise show all-or-nothing behavior at the absolute refractory period, whereas the amplitude of the compound action potential, when the interstimulus interval approached the refractory period, would gradually decrease as more and more of the fibers in the sample would become refractory (Fig. 6A,D). In the example shown in Figure $6 B$, the conditioned action potential $\left(r_{2}\right)$ disappeared when the interstimulus interval was reduced from 3.0 to $2.9 \mathrm{msec}$. This indicated that the spike component shown reacted in an all-or-nothing fashion. The eight potentials from different nerves tested by double stimulation all demonstrated a constant amplitude (within limits set by noise) during the relative refractory period and occlusion of the potential at the absolute refractory period that varied between 0.8 and $3.0 \mathrm{msec}$. The absolute and the relative refractory 

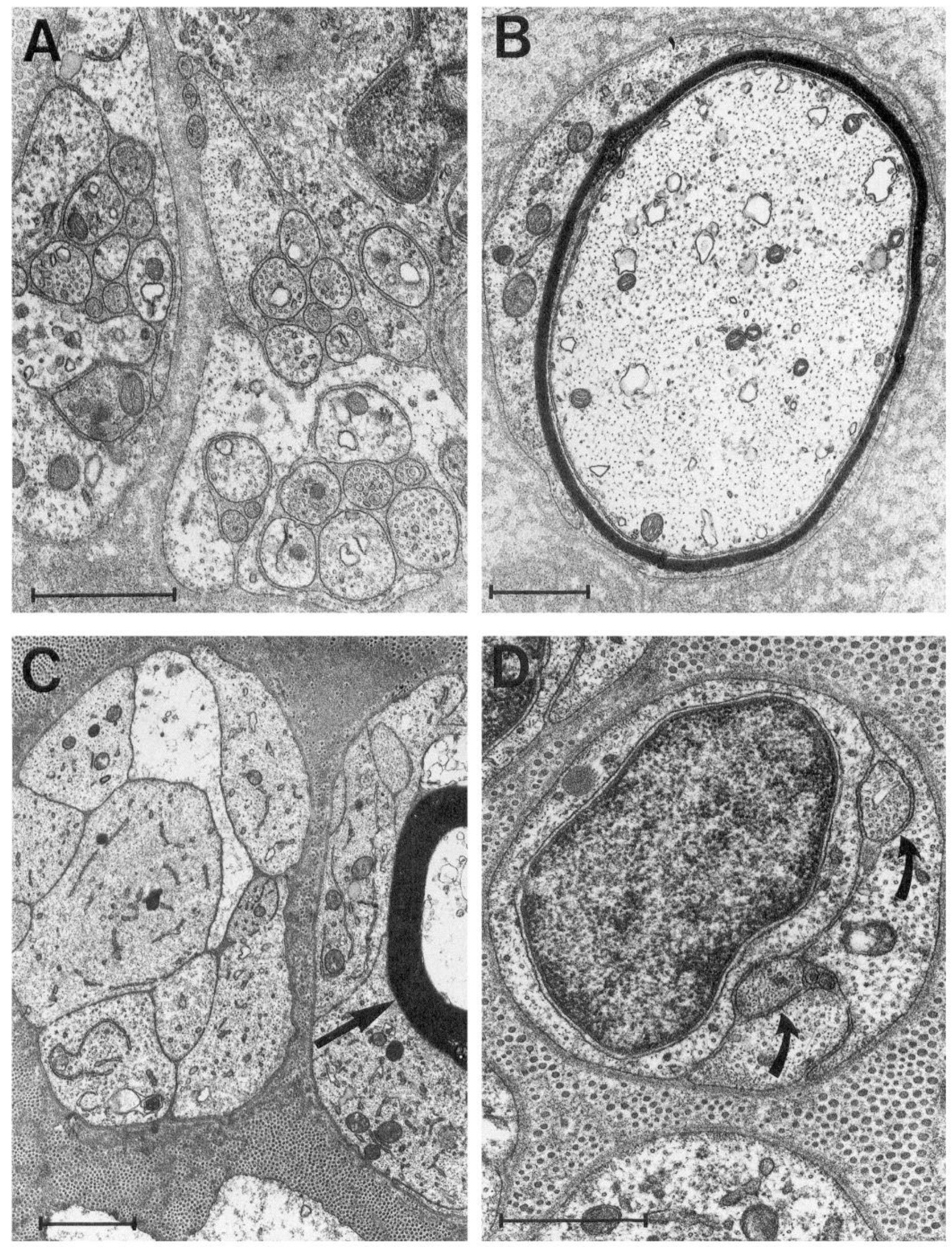


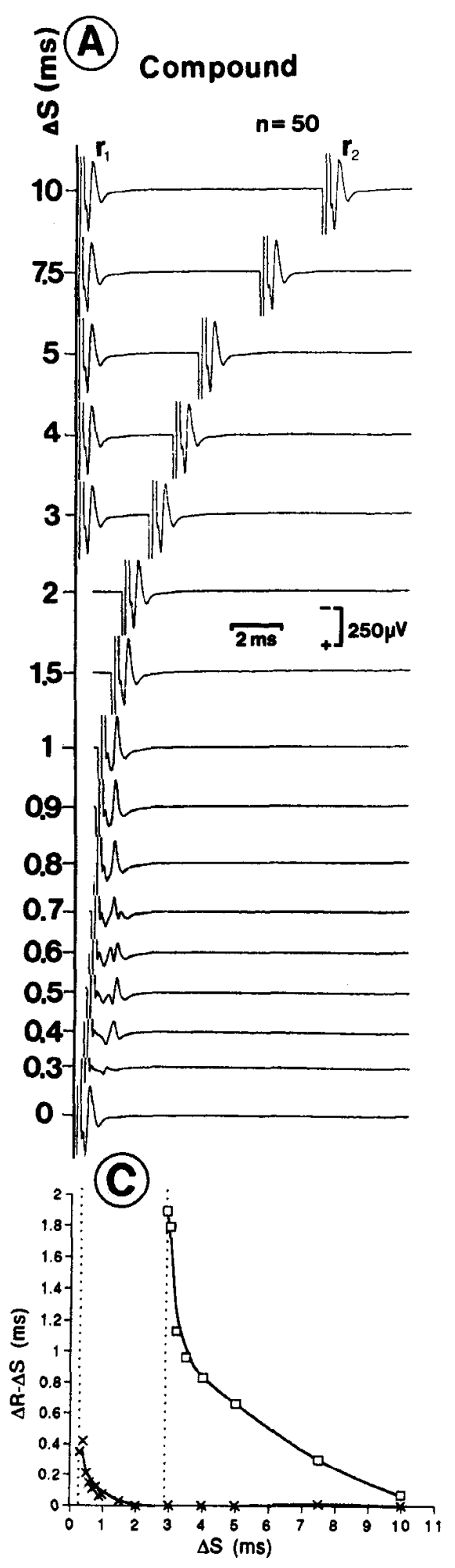

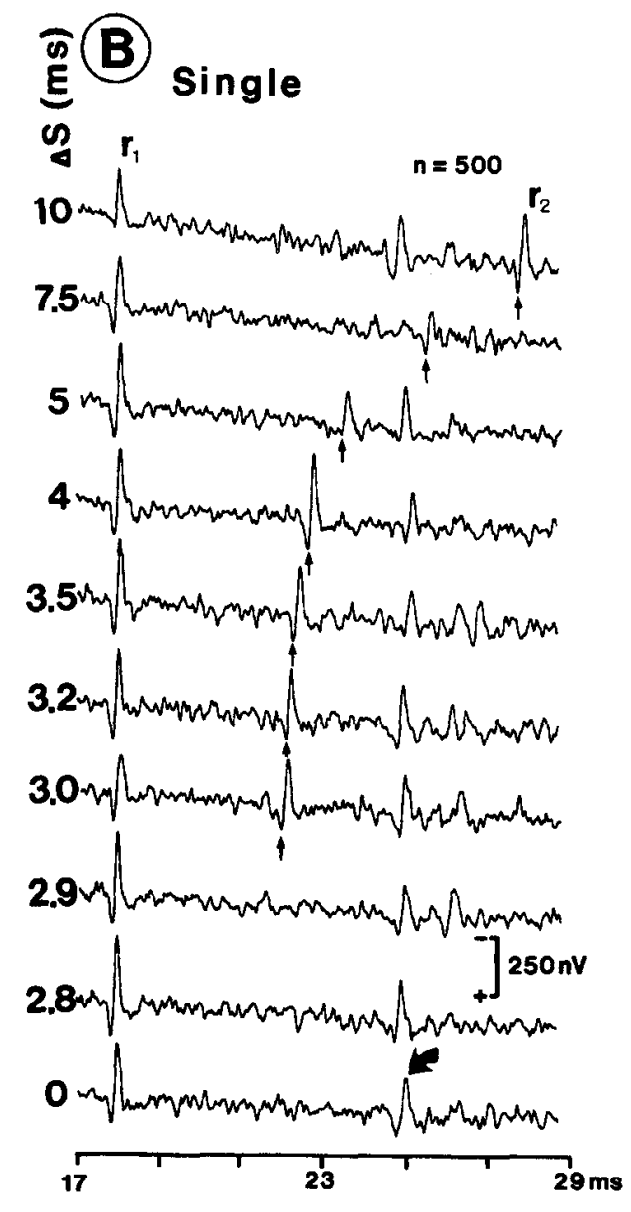

Figure 6. The refractory periods of the compound action potential of a normal nerve $(A)$ and of a single fiber potential of a regenerated nerve $(B)(n$, number of responses averaged; $r_{l}$, unconditioned response; $r_{2}$, conditioned response; $\Delta S$, interval between first and second stimulus; $\Delta R$, interval between $r_{1}$ and $\left.r_{2}\right) . A, r_{2}$ gradually decreased in amplitude with decreasing $\Delta S$, and was absent when $\Delta S<0.3$ msec. The unconditioned response $\left(r_{l}\right)$ was electronically subtracted from the double response at $\Delta S$ of less than 2 msec to show the conditioned response $\left(r_{2}\right)$ undisturbed. The tibial nerve was stimulated at cathode 13 and the response was recorded with tripolar electrode configuration in the tibial cuff at leads $9-7 / 8$ (see Fig. 1). $B, r$, had a latency of 17.8 msec (recorded with a delay of $17 \mathrm{msec}$ ). $r_{2}$ (small arrows) disappeared in an allor-nothing fashion at $\Delta S \leq 2.9 \mathrm{msec}$. The refractory period of a second response with a latency of $24.8 \mathrm{msec}$ (large curved arrow) was not examined. The tibial nerve was stimulated at cathode 10 and the response recorded at $\mathbf{R}_{1}$ (see Fig. 1). $C$, The difference between the interresponse $(\Delta R)$ and the interstimulus $(\Delta S)$ interval $(\Delta R-\Delta S)$ as a function of $\Delta S$ for the action potential of the normal nerve $(x)$ and for the action potential of the regenerated fiber response $(\square)$ during the relative refractory period. The dotted lines indicate the absolute refractory period. $D$, Amplitude of $r_{2}$ of the normal nerve action potential $(x)$ and of the regenerated fiber $(\square)$ as a function of $\Delta S\left(r_{1}=100 \%\right)$. Note the gradual decline of the $r_{2}$ for the compound action potential in contrast to the sudden complete loss of the single fiber response at $\Delta S<3.0 \mathrm{msec}$.

Figure 5. Electron micrographs of axon and questionable axonal sprouts. $A$ and $B$ correspond to level 8 (excitable), and $C$ and $D$, to level 13 (not excitable), in Figure $4 A . A$, Numerous axonal sprouts in two bands of Büngner are present. $B$, Thinly myelinated regenerated fiber representing the most mature fibers at this level. $C$, A band of Büngner containing no axons (left $)$ and a part of an almost intact myelin sheath that does not contain an axon (arrow, right). D, A small band of Büngner consisting of Schwann cells and two cellular processes (curved arrows) that may be axonal sprouts. Scale bars: $A, B$, and $D, 1 \mu \mathrm{m} ; C, 2 \mu \mathrm{m}$. 


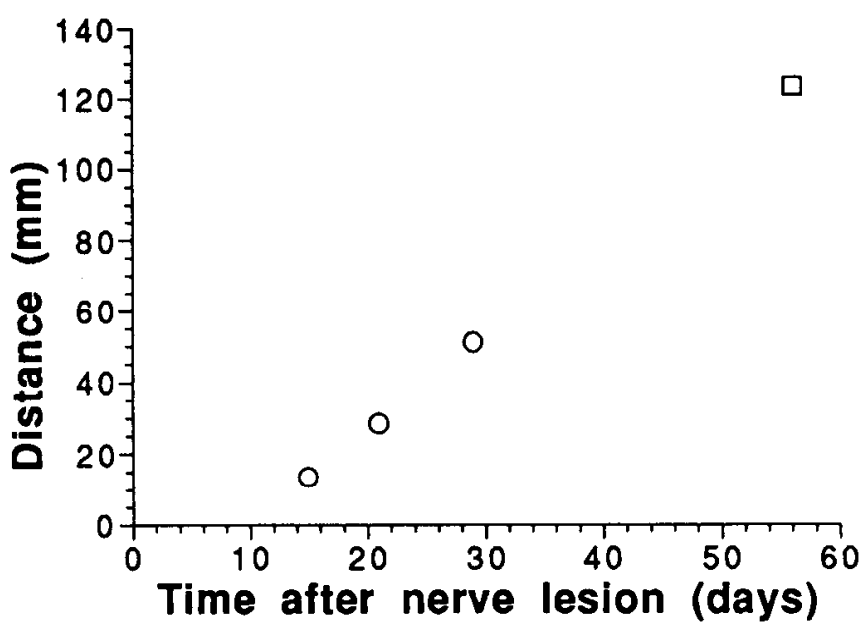

Figure 7. Scatterplot to show distance of regeneration (ordinate) at serial studies (time after nerve lesion; abscissa) after sectioning of one tibial nerve. The recordings were repeated weekly to determine the site of the most distal nerve response $(O)$ and when a muscle response could be recorded for the first time ( $\square$ ).

periods of these responses originating from promyelinated fibers were 3-10 times longer than in unlesioned nerve (Fig. $6 C, D$ ).

\section{Rate of elongation}

The front of regenerating fibers was followed through the tibial cuff by serial observations of the most distal site of excitability; subsequently, the time was determined at which a response could first be recorded from the plantar muscles. The distance versus time relationship of these longitudinal studies of elongation was linear, suggesting that the rate of elongation of excitable fibers was constant after an initial delay (Fig. 7).

Reinnervation of plantar muscle took place earlier after crushing than after sectioning (42-54 d vs $42-84 \mathrm{~d}$, freeze experiments included; $P<0.001$, Mann-Whitney $U$ test). The fiber front had regenerated a shorter distance after sectioning than after crushing in the recordings carried out $16 \mathrm{~d}$ after the lesion (Fig. 4), also suggesting a later regeneration after sectioning than after crushing. The slope of the pooled distance versus time relationship indicated an elongation rate after sectioning $(2.5 \mathrm{~mm} /$ d; Fig. $8 B$ ) that was $22 \%$ lower $[P<0.01, t$ test of the slopes of the regression lines (Zar, 1984)] than after crushing $(3.2 \mathrm{~mm} /$ day; Fig. $8 A$ ). In the individual nerves with sufficient data points to calculate regression coefficients, the elongation rates estimated from the slopes also indicated that elongation was faster after crushing (3.6 $\pm 0.7 \mathrm{~mm} / \mathrm{d}, n=5$, mean $\pm \mathrm{SEM})$ than after sectioning $(2.7 \pm 0.2 \mathrm{~mm} / \mathrm{d}, n=10 ; P<0.01$, Mann-Whitney $U$ test).

The sites along the nerves with regenerating fibers present were closely similar in experiments with crushing of one tibial nerve and crush + freeze of the contralateral nerve (Fig. $8 A$ ). Because of this congruence, we limited the number of longitu-

Figure 8. Scatterplots (pooled experiments) to compare the regeneration distance (ordinate) versus time (abscissa) relationship after crushing and crush + freeze $(A)$, sectioning and section + freeze $(B)$, and at expanded scale during early regeneration after sectioning and section + freeze $(C)$. Data points (nerve action potentials: circles in $A$ and $B$, circles and triangles in $C$; muscle action potential, squares) were
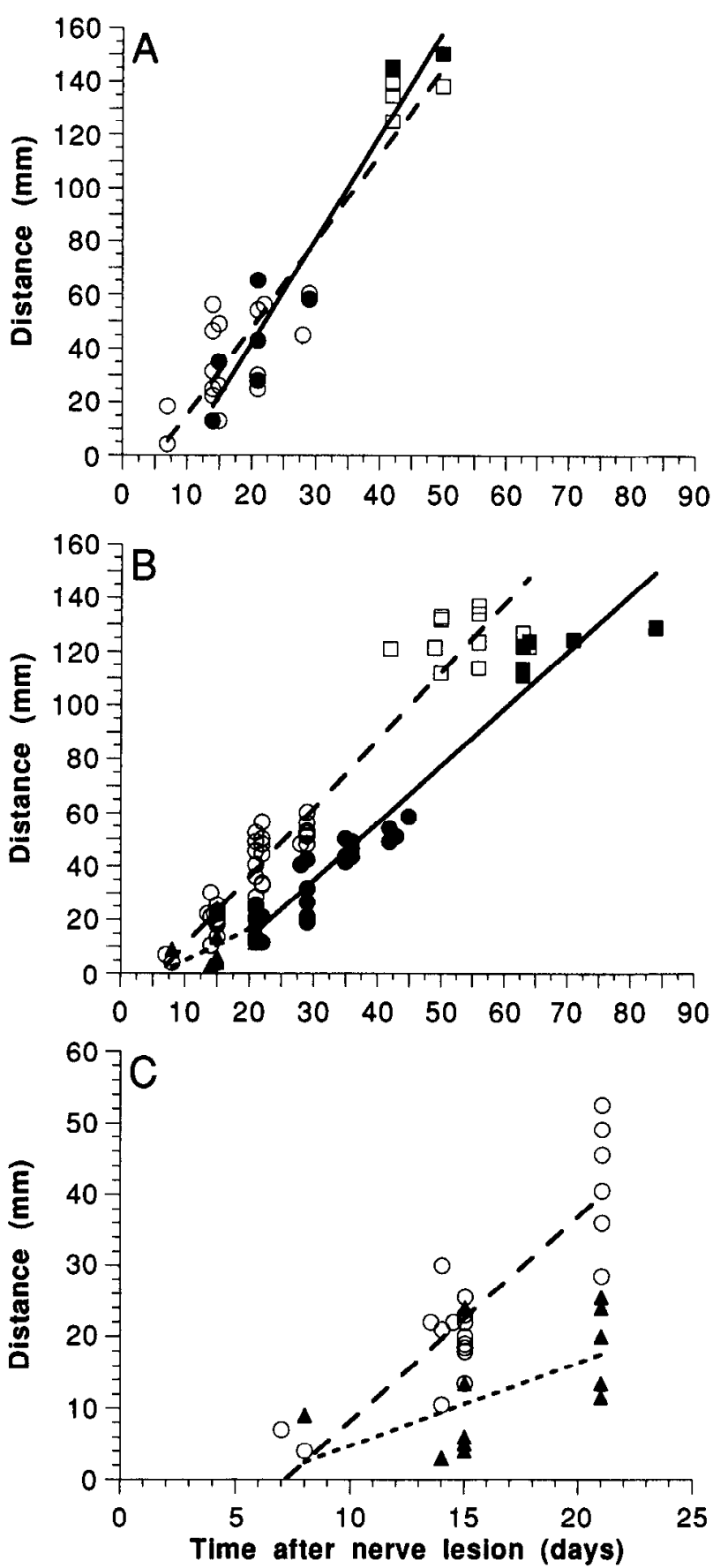

obtained as in Figure 7. Open symbols, crushing and sectioning alone; solid symbols, crush + freeze and section + freeze. Regression lines (longdash lines, crushing and sectioning alone; solid and short-dash lines, crush + freeze and section + freeze) were calculated by the method of least squares. The linear regression equations were as follows. Distance $=a$ $\left( \pm S_{y \cdot x}\right) \mathrm{mm}+b\left( \pm S_{b}\right) \mathrm{mm} / \mathrm{d} \times$ days after nerve lesion, where $S_{y \cdot x}$ is the SE of the estimate and $S_{b}$ the SE of the slope. Intercept indicates time intercept at zero distance. In $A$, for crushing, distance $=-17.3$ $( \pm 16.2) \mathrm{mm}+3.23( \pm 0.3) \mathrm{mm} / \mathrm{d} \times$ days, $r=0.9286, n=20, P<$ 0.001 , intercept $=5 \mathrm{~d}$; for crush + freeze, distance $=-35.8( \pm 15.2) \mathrm{mm}$ $+3.87( \pm 0.4) \mathrm{mm} / \mathrm{d} \times$ days, $r=0.9568, n=8, P<0.01$, intercept $=$ $9 \mathrm{~d}$. In $B$, for sectioning, distance $=-15.0( \pm 10.2) \mathrm{mm}+2.54( \pm 0.09)$ $\mathrm{mm} / \mathrm{d} \times$ days, $r=0.9686, n=49, P<0.001$, intercept $=6 \mathrm{~d}$; for section + freeze, the relationship was described by two linear regression lines (for early regeneration ( $<21 \mathrm{~d}$ after the nerve lesion) the regression is shown at expanded scale $(C)$; early, distance $=-7.0( \pm 7.0) \mathrm{mm}+$ $1.16( \pm 0.5) \mathrm{mm} / \mathrm{d} \times$ days, $r=0.5601, n=13, P \leq 0.05$, intercept $=$ $6 \mathrm{~d}$; late, distance $=29.7( \pm 4.2) \mathrm{mm}+2.14( \pm 0.05) \mathrm{mm} / \mathrm{d} \times$ days, $r=0.9705, n=29, P<0.001$. 
dinal experiments with crush + freeze to three nerves. The rate of elongation of the pooled observations after crush + freeze was $3.9 \mathrm{~mm} / \mathrm{d}$, which did not differ from that after crushing alone $(P>0.5, t$ test; Fig. $8 A)$.

In contrast to nerve crushing compared with crush + freeze, the regeneration after section + freeze lagged behind that after sectioning alone. Plantar muscle reinnervation occurred 63-84 $\mathrm{d}$ after section + freeze and 42-64 d after sectioning $(P<0.005$, Mann-Whitney $U$ test). The distance versus time relationship of the pooled observations (Fig. $8 B$ ) showed that the observations were delayed at each distance after section + freeze compared with sectioning alone. This difference suggested that two linear functions could describe the regeneration after section + freeze: during the first 3 weeks the elongation rate was 1.2 $\mathrm{mm} / \mathrm{d}$ (Fig. 8B,C) through the frozen portion of the nerve that was partially covered by the cuff electrode; after 3 weeks this early phase with a low rate had caused a significant shift $(P<$ $0.001, t$ test) of the regression line compared with that after sectioning alone (Fig. $8 \mathrm{~B}$ ). The initial low elongation rate after section + freeze was 59\% lower than after sectioning alone (shown at an expanded scale in Fig. 8C); the difference between the slopes was significant $(P<0.01, t$ test). The elongation rates after sectioning alone and after section + freeze did not differ significantly after the first 3 weeks.

Regeneration at the electrode site close to the lesion was difficult to examine with this experimental setup (see Discussion). The most proximal electrode was placed $1-10 \mathrm{~mm}$ distal to the lesion site, and the elongation rate just distal to the lesion site could not be measured accurately. Due to this inaccuracy, the regeneration delay was estimated from the extrapolated intercepts of the regression lines at zero distance. The delays estimated in this fashion were 5-9 d and did not differ significantly after crushing, crush + freeze, sectioning, and the early phase of section + freeze (analysis of covariance; Zar, 1984).

\section{Conduction velocities}

The highest conduction velocity of action potentials when first detected was $0.5-2 \mathrm{~m} / \mathrm{sec}$ along the regenerated nerve segment, corresponding to less than $2 \%$ of controls (Figs. 4,9$)$. The polyphasic response contained late components, indicating that some regenerated fibers had even lower conduction velocities. The conduction velocity increased during early regeneration, even before the axons had reached their target organs. The increase was continuous as it could be seen when the nerve was investigated at an interval of $24 \mathrm{hr}$ (Fig. 10). In parallel with this maturation, the number of spikes elicited from the most distal electrode increased, indicating that more excitable axons had regenerated to this level between the recording sessions.

At the time when the regenerating axons had reached the muscle, the maximum conduction velocity was higher in nerves that had been sectioned $(20-35 \mathrm{~m} / \mathrm{sec})$ than in nerves that had been crushed (10-15 m/scc; Fig. 9). The increase in conduction velocity occurred later distally than proximally along the regenerated segment, which indicated a gradient of maturation along the regenerated axons.

\section{Amplitudes of early nerve action potentials}

The number of spikes that could be elicited during early regeneration from a given electrode increased from recording session to recording session, suggesting that more and more axons reached this level (Fig. 11). These spikes were widely dispersed ( 29 and 36 d; Fig. 11) but the latency differences became smaller
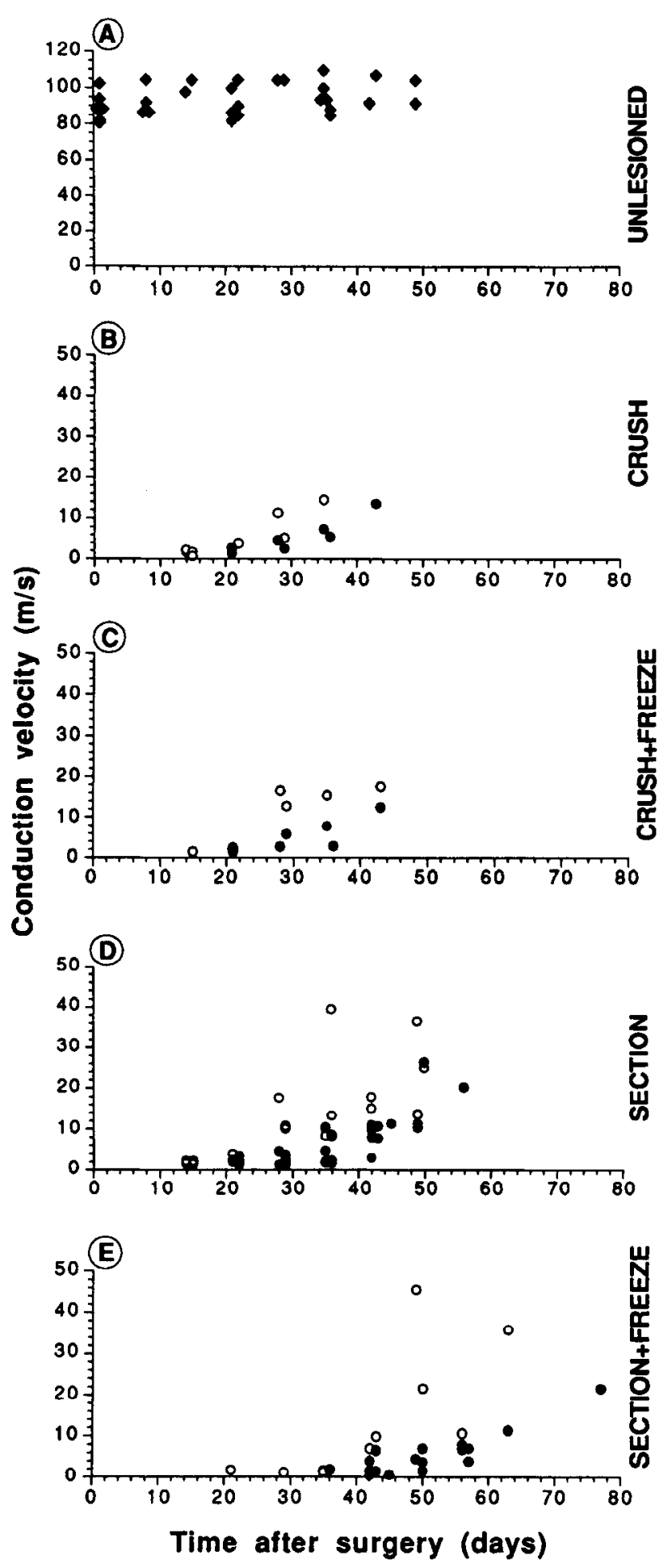

Figure 9. Maximal conduction velocities along control tibial nerves $(A)$ and along regenerated tibial nerves $(B-E)$ as a function of time after surgery. $A$, In control nerves, the velocity was calculated from the difference in latency between the most proximal (cathode 7, Fig. 1) and the most distal stimulus site (cathode 13). The implanted electrodes did not cause a change in the conduction velocity. $B-E$, The conduction velocities were calculated from the differences in latencies along two segments proximally (open symbols, cathodes 7-9) and distally (solid symbols, cathodes $11-13$ ) in the tibial nerve. Note the continuous increase with time after surgery. 


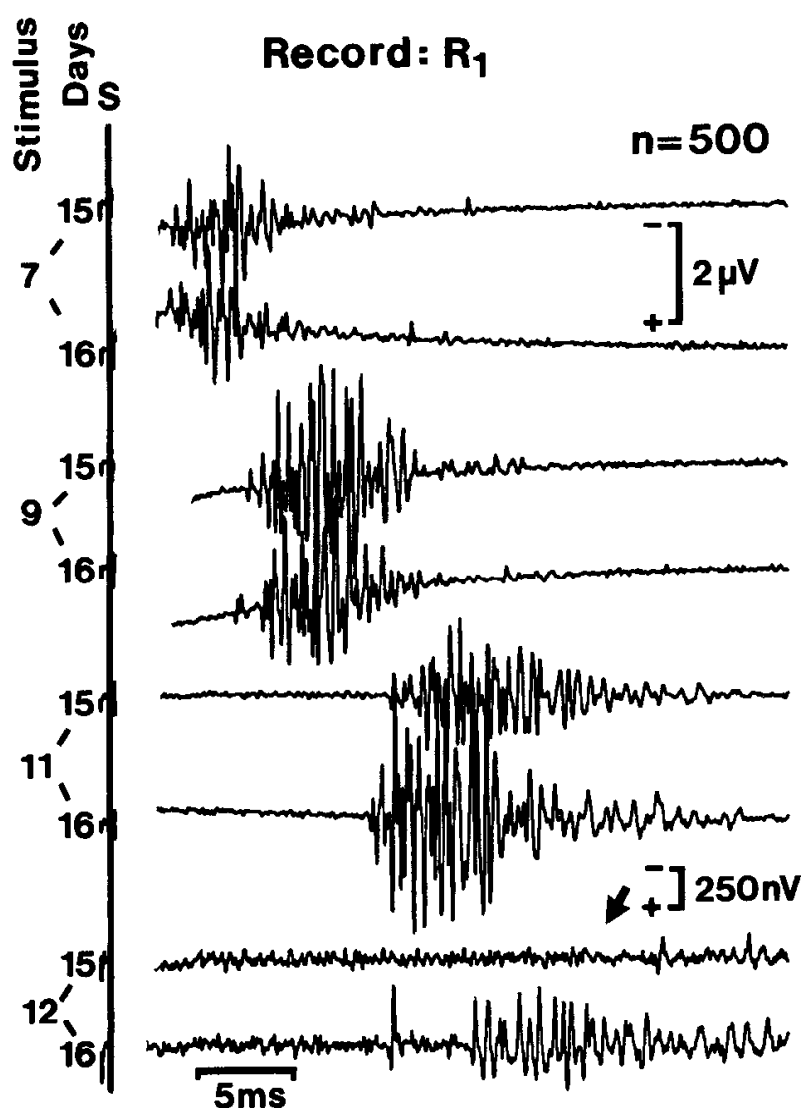

Figure 10. Nerve action potentials from a nerve regenerating after crushing recorded with $24 \mathrm{hr}$ interval at days 15 and 16 to show maturation and elongation of regenerating nerve fibers. The stimulus $(S)$ was applied at cathodes $7,9,11$, and 12 (Fig. 1) to the tibial nerve and the action potential was recorded at $R_{f}$ at the sciatic nerve ( $n$, number of responses averaged). Within $24 \mathrm{hr}$, the latencies decreased; the number of spikes that could be elicited at cathode 12 increased from few to a burst of spikes (lowermost two traces).

and the amplitude increased by the time reinnervation of the plantar muscles had occurred (56 d; Fig. 11).

There was a tendency of the peak-to-peak amplitudes to increase during the early regeneration (from $0.2-0.5 \%$ of normal to $5 \%$ of normal). Beyond $30 \mathrm{~d}$, this process seemed to be faster after crushing and crush + freeze than after sectioning (Fig. 12), probably because more axons reached the site of stimulus after this time in crushed nerves than in sectioned nerves. After section + freeze, the response remained dispersed and the amplitude increased little if at all throughout the observation period.

\section{Discussion}

Nerve regeneration after Wallerian degeneration was monitored by means of implanted electrodes in order to examine the influence of Schwann cells on early axon growth. Our results suggest that intact basal lamina tubes are equally and possibly more important for axonal outgrowth than the presence of Schwann cells. Before commenting on these results, we wish to discuss the problems connected with the relatively new approach of chronic in vivo recording from regenerating nerves.

\section{Methodological considerations}

The critical points of monitoring outgrowth and maturation of regenerating axons by implanted electrodes over a prolonged

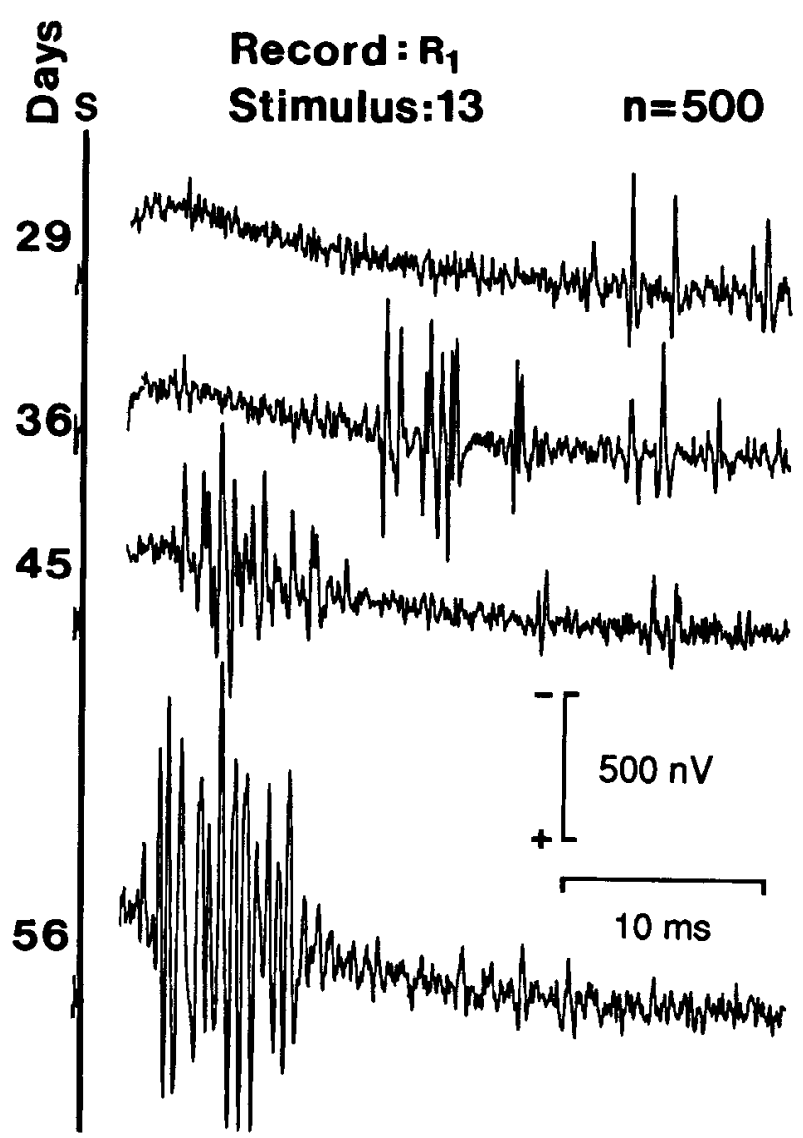

Figure 11. Nerve action potentials to show maturation $29-56 \mathrm{~d}$ after nerve sectioning. The stimulus $(S)$ was applied to the tibial nerve at cathode 13 (see Fig. 1) and the evoked action potential was recorded with tripolar electrode configuration at the sciatic nerve $\left(R_{f} ; n\right.$, number of averaged responses). The latency decreased gradually from $25 \mathrm{msec}$ at day 29 to $3 \mathrm{msec}$ at day 56 . The number of spikes increased markedly whereas the peak-to-peak amplitude did not increase correspondingly, probably due to poor synchronization with variable summation and phase cancellation.

period of time are that the position and electrical properties of the electrodes remain stable, and that they do not damage the nerve.

Immediately after implantation of the electrodes, the nerves might slide $1-2 \mathrm{~mm}$ in relation to the cuff, but connective tissue adhesions between electrode and nerve formed within $1-2$ weeks and prevented further changes of the nerve-cuff relationship. The electrodes remained electrically stable, as shown by their constant low impedance. They usually did not damage the nerve (Krarup and Loeb, 1988), and serial recording of compound action potentials from unlesioned nerves disclosed no general deterioration. The amplitude of the action potential of the nerve declined initially by at most $50 \%$; this was probably due to formation of connective tissue inside the cuffs. The conduction velocity of the nerve and the amplitude of the muscle action potential were unaffected (Fig. 9A). In a few instances, however, compression of the sciatic nerve was clinically obvious; these experiments were discontinued.

\section{Recording and stimulation}

Action potentials of single myelinated fibers can be recorded by a nerve-cuff electrode in unlesioned nerves (Rindos et al., 1984; 
Krarup and Loeb, 1988), provided the fibers are larger than 5$7 \mu \mathrm{m}$; the responses of smaller fibers with action potentials of less than $0.1-0.15 \mu \mathrm{V}$ cannot be distinguished from noise even after averaging of 500 responses (Krarup et al., 1988). Therefore, early regeneration could not be assessed by recording action potentials from the few unmyclinatcd axons at the front of regenerating fibers. In order to evaluate the activity from these axons, we have taken advantage of the amplification of the action potentials that occurs when they are propagated from the unmyelinated to the myelinated portion of the regenerating axon. This amplification made it possible to record activity originating even from single regenerated nerve fibers.

The high stimulus strength necessary to activate the promyelinated nerve fibers made the exact site of excitation in relation to the stimulating cathode uncertain. The increase in latency, however, which was seen when the cathode site was moved distally, indicated that the site of excitation was also moved distally. A gradient of conduction velocity was found along the tibial nerves. This also supports the notion that the axons were stimulated at the site of the cathodes rather than at distant (proximal) sites with low threshold. In addition, fewer fibers were activated at more distal sites; this corresponded to findings at electron microscopic examination. Electron microscopy at the most distal excitable site revealed only unmyelinated axons. Questionable axonal sprouts were found $7-8 \mathrm{~mm}$ distal to the last lead from which a response could be evoked (Fig. 5D). If they were axonal sprouts, they might have been unexcitable because their membranes still contained an insufficient number of voltage sensitive sodium channels (Waxman and Black, 1985; Wood et al., 1992). Alternatively, they might have been sprouts that were so thin that their action current was insufficient to excite the proximal part of the nerve fiber at the transition between the unmyelinated and the myelinated part of the fiber (Goldstein and Rall, 1974). A third possibility could be that the sprouts originated from unmyelinated fibers or from small myelinated fibers with a diameter of less than $6-7 \mu \mathrm{m}$.

\section{Maturation during early regeneration}

The conduction velocities measured during early regeneration and the histological studies showed that distal propagation occurred along unmyelinated axons. Maturation, that is, myelination and increase of fiber diameter, occurred before the axons had reached their target organs, suggesting that maturation progressed in a proximodistal direction. Conduction was faster along the proximal scgments of the regenerated nerve segment than distally. Comparisons of crush and section lesions (Fig. 9B,D) suggested that the conduction velocities along the regenerated tibial nerve increased gradually at about the same rate. At the time of reinnervation of the plantar muscle, the conduction velocity distal to a crush lesion was lower than distal to a section lesion (with or without freezing). The outgrowing axons reached the muscle earlier after a crush than after a section lesion; this may explain why maturation at that time was more advanced in sectioned nerves. The above-mentioned difference in increase of the conduction velocity between crush and section lesions might suggest that the time after the lesion rather than the distance over which the axons had grown determined the progress of maturation of regenerated axons, and that the rate of maturation is different from the rate of elongation. Maturation occurs as a complex interaction between proximal-to-distal growth of Schwann cells and cellular contacts between neurite and Schwann cell membranes (Pellegrino and Spencer, 1985). Such

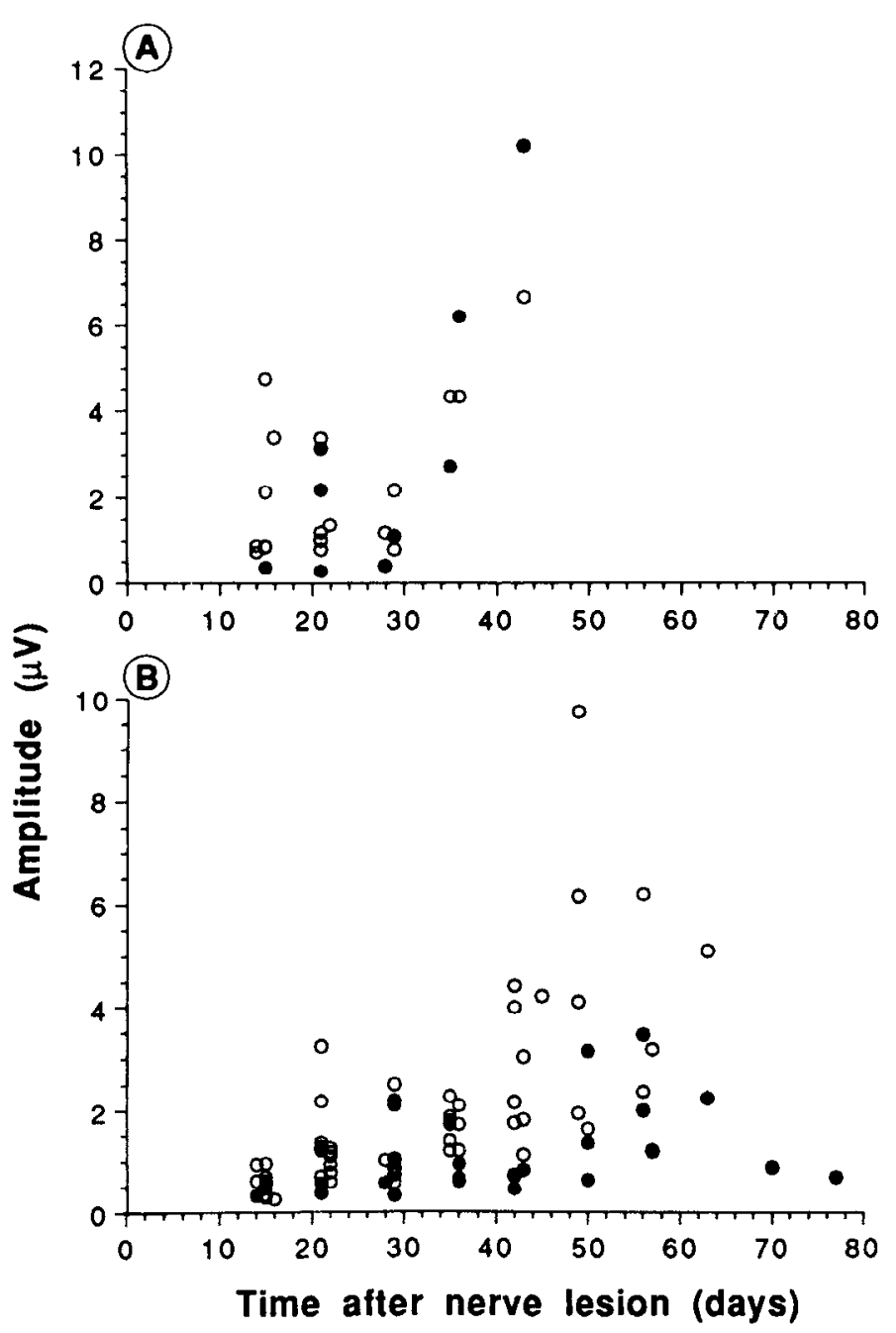

Figure 12. Peak-to-peak amplitudes of the nerve action potentials versus time after crushing (open symbols) or crush + freeze (solid symbols) $(A)$, or sectioning (open symbols) or section + freeze (solid symbols) $(B)$. The response was evoked in the proximal part of the tibial cuff (cathode 9, Fig. 1) and recorded at $R_{1}$ in the sciatic nerve.

interaction might have kinetics that explain that the progression of maturation may be similar after crushing and sectioning even though the rate of elongation differed.

\section{Number of regenerated fibers}

Poor synchronization and phase cancellation made the peakto-peak amplitude an inaccurate indicator of the number of fibers establishing the response. The increase of the amplitude of the action potential of nerve was apparently slower after sectioning than after crushing (Fig. 12). This suggests that fewer fibers regenerated after sectioning than after crushing. Freezing did not change the amplitudes in crushed nerves, whereas the amplitudes remained low throughout the observation period after section + freeze (Fig. 12). This was probably due to the fact that fewer fibers had regenerated and that the response remained more dispersed than after sectioning alone.

\section{Rate of clongation}

The rate of elongation was determined by following the front of excitability in serial electrophysiological studies; after an initial delay the rate was constant. This is in agreement with pre- 
vious studies(Young and Medawar, 1940; Gutmann et al., 1941; Sjöberg and Kanje, 1990). Extrapolation of the regression curves suggested the initial delay to be about 5-6 d. However, regeneration just distal to the lesion site could not be accurately assessed, both due to the fixed distance of $7.5 \mathrm{~mm}$ between stimulus sites and because fibers proximal to the lesion site were often excited by the proximal cathode in the tibial cuff. Our method therefore did not allow detection of the gradual nonlinear initial increase in the rate of elongation as it can be seen by the pinch technique (Sjöberg and Kanje, 1990), in which location of the front of regenerating fibers is assessed by pinching the regenerating nerve stepwise in the distal-proximal direction until a reflex response is seen (Gutmann et al., 1941).

The rate of elongation after crushing was $3-4 \mathrm{~mm} / \mathrm{d}$; this confirmed previous results obtained by the same technique (Krarup et al., 1988) and by the pinch technique in the rabbit (Gutmann et al., 1941) and in the rat (Sjöberg et al., 1988; Bresjanac and Sketelj, 1989; Sketelj et al., 1989; Sjöberg and Kanje, 1990). The timing of the first muscle response recorded from the plantar muscles was seen to fall along the same linear regression group as the nerve action potentials elicited in the tibial cuff (Fig. 7), suggesting (1) that motor fibers regenerated at least as fast as sensory fibers and (2) that the delay caused by establishing functional neuromuscular transmission was small as compared to the speed of axonal outgrowth $(\mathrm{Ko}, 1984)$. After nerve sectioning, the rate of elongation was about $25 \%$ lower than after crushing; this confirmed the findings of Gutmann et al. (1941). The different elongation rates found after section and crush Icsions (Fig. 8) demonstrates that slowing of regeneration occurred throughout the distal part of the nerve. Whether the possible mismatch between regenerating fibers and Schwann cell tubes after nerve sectioning as opposed to crushing (Haftek and Thomas, 1968), or whether other factors, such as impairment of axonal transport, were responsible for the slower axonal growth remains obscure. Regeneration after crushing combined with a focal constriction showed a similar reduction in elongation rate throughout the distal nerve (Krarup et al., 1988). It might be considered whether the slower elongation after sectioning than after crushing could be explained by a more marked Schwann cell loss (Weinberg and Spencer, 1978) after sectioning than after crushing due to a longer delay at the site of the lesion. This possibility seems unlikely considering that the initial delays in regeneration assessed by the time intercepts of the distance versus time relationships (Fig. 8A,C) were the same after both lesions.

\section{Depletion of Schwann cells}

Freezing of the nerve distal to a crush lesion caused loss of Schwann cells but had no effect on the rate of elongation. In agreement with our results, Sjöberg et al. (1988) found that the elongation rate was unchanged provided an unfrozen nerve segment was left intact distal to the frozen segment; a reduced rate of elongation was found when the entire distal nerve segment was frozen. Electron micrographs of the frozen nerve segment distal to a crush lesion showed that axons regenerated through basal lamina tubes devoid of Schwann cells, indicating that the normal rate of elongation was not due to migration of Schwann cells ahead of axons. This is in agreement with the findings that sprout formation and axonal elongation can occur independently of Schwann cells (Ide et al., 1983; Tomaselli et al., 1986; Sketelj et al., 1989; Nadim et al., 1990), and that basal lamina material in vitro supports sprout outgrowth in the absence of
Schwann cells (Ard et al., 1987). Wang et al. (1992) found that neurites were misguided outside the empty basal lamina tubes when the frozen nerve graft was pretreated with anti-laminin antibody. It is unknown how far ahead of Schwann cells axons can regenerate. It is well established, however, that axonal regeneration over long distances and maturation of nerve fibers depend on the presence of Schwann cells (Hall, 1986; Sjöberg and Kanje, 1988; Bresjanac and Sketelj, 1989; Nadim et al., 1990).

In contrast to the inconspicuous effect of freezing on nerve regeneration distal to a crush, freezing over $20-25 \mathrm{~mm}$ distal to a section lesion was associated with slowed elongation through the frozen segment. Elongation accelerated distal to the frozen area and became similar to that after sectioning alone. Hence, Schwann cell depletion distal to the lesion became more important for axonal outgrowth when the basal lamina tubes were severed (section +freeze) than when they were intact (crush + freeze). Ultrastructural studies of nerve regeneration across the gap after a section lesion have shown that Schwann cell columns are formed both from the proximal and from the distal stump (Thomas, 1966). The impaired regeneration after section + frecze cxperiments might be due to the fact that the distal stump could not contribute Schwann cells to such columns. Ide et al. (1983) also demonstrated axonal regeneration through acellular nerve grafts, and it might be speculated that the rate of migration or proliferation or both of the Schwann cells from the proximal nerve stump under such circumstances become essential and influence the rate of axonal elongation. Alternatively, one might suggest that the slowed elongation in the section+freeze experiments was due to deficiency of diffusible factors (Politis et al., 1982) released by Schwann cells distal to the frozen segment. Diffusion of such factors could be reduced if the basal lamina tubes were interrupted. Also in this case, the speed at which Schwann cells comigrate with the axons could limit the rate of axonal elongation (Hall, 1986; Thomas, 1989).

\section{References}

Ard MD, Bunge RP, Bunge MB (1987) Comparison of the Schwann cell surface and Schwann cell extracellular matrix as promoters of neurite growth. J Neurocytol 16:539-555.

Berry CM, Grundfest H, Hinsey JC (1944) The electrical activity of regenerating nerves in the cat. J Neurophysiol 7:103-115.

Bresjanac M, Sketelj J (1989) Neurite-promoting influences of proliferating Schwann cells and target-tissues are not prerequisite for rapid axonal elongation after nerve crush. J Neurosci Res 24:501-507.

Brushart TME (1988) Preferential reinnervation of motor nerves by regenerating motor axons. J Neurosci 8:1026-1031.

Brushart TME (1990) Preferential motor reinnervation: a sequential double-labeling study. Restor Neurol Neurosci 1:281-287.

Davis LA, Gordon T, Hoffer JA, Jhamandas J, Stein RB (1978) Compound action potentials recorded from mammalian peripheral nerves following ligation or resuturing. J Physiol (Lond) 285:543-559.

Feasby TE, Bostock H, Sears TA (1981) Conduction in regenerating dorsal root fibers. J Neurol Sci 49:439-454.

Fugleholm K, Krarup C (1992) The influence of Schwann cells on early peripheral nerve regeneration studied by chronically implanted electrodes in the cat. Soc Neurosci Abstr 18:1463.

Gilliatt RW, Hjorth RJ (1972) Nerve conduction during Wallerian degeneration in the baboon. J Neurol Neurosurg Psychiatry 35:335341 .

Goldstein S, Rall W (1974) Changes of action potential shape and velocity for changing core conductor geometry. Biophys J 14:731757.

Gutmann E, Guttmann L, Medawar PB, Young JZ (1941) The rate of regeneration of nerve. J Exp Biol 19:14-44.

Haftek J, Thomas PK (1968) Electron-microscope observations on 
the effects of localized crush injuries on the connective tissues of peripheral nerve. J Anat 103:233-243.

Hall SM (1986) The effect of inhibiting Schwann cell mitosis on the re-innervation of acellular autografts in the peripheral nervous system of the mouse. Neuropathol Appl Neurobiol 12:401-414.

Hodes R, Larrabee MG, German W (1948) The human electromyogram in response to nerve stimulation and the conduction velocity of motor axons. Arch Neurol Psychiatry 60:340-365.

Ide C, Tohyama K, Yokota R, Nitatori T, Onodera S (1983) Schwann cell basal lamina and nerve regeneration. Brain Res 288:61-75.

Jacobson S, Guth L (1965) An electrical study of the early stages of peripheral nerve regeneration. Exp Neurol 11:48-60.

Ko C (1984) Regeneration of the active zone at the frog neuromuscular junction. J Cell Biol 98:1685-1695.

Krarup C, Gilliatt RW (1985) Some effects of prolonged constriction on nerve regeneration in the rabbit. J Neurol Sci 68:1-14.

Krarup C, Loeb GE (1988) Conduction studies in peripheral cat nerve using implanted electrodes. I. Methods and findings in controls. Muscle Nerve 11:922-932.

Krarup C, Loeb GE, Pezeshkpour GH (1988) Conduction studies in pcripheral cat nerve using implanted electrodes. II. The effects of prolonged constriction on regeneration of crushed nerve fibers. Muscle Nerve 11:933-944.

Lundborg G, Dahlin L, Danielson A, Nachemson K (1986) Tissue specificity in nerve regeneration. Scand J Plast Reconstr Surg 20:279283.

Mackinnon SE, Dellon AL, Lundborg G, Hudson MB, Hunter DA (1986) A study of neurotrophism in a primate model. J Hand Surg 11A:888-893.

Nadim W, Anderson PN, Turmaine M (1990) The role of Schwann cells and basal lamina tubes in the regeneration of axons through long lengths of freeze-killed nerve grafts. Neuropathol Appl Neurobiol 16: $411-421$.

Pellegrino RG, Spencer PS (1985) Schwann cell mitosis in response to regenerating peripheral axons in vivo. Brain Res 341:16-25.

Politis MJ, Ederle K, Spencer PS (1982) Tropism in nerve regeneration in vivo. Attraction of regenerating axons by diffusible factors derived from cells in distal nerve stumps of transected peripheral nerves. Brain Res 253:1-12.

Rindos AJ, Loeb GE, Levitan H (1984) Conduction velocity changes along lumbar primary afferent fibers in cats. Exp Neurol 86:208-226.

Sjöberg J, Kanje M (1990) The initial period of peripheral nerve regeneration and the importance of the local environment for the conditioning lesion effect. Brain Res 529:79-84.
Sjöberg J, Kanje M, Edström A (1988) Influence of non-neuronal cells on regeneration of the rat sciatic nerve. Brain Res 453:221-226.

Sketelj J, Bresjanac M, Popovic M (1989) Rapid growth of regenerating axons across the segments of sciatic nerve devoid of Schwann cells. J Neurosci Res 24:153-162.

Stein RB, Pearson KG (1971) Predicted amplitude and form of action potentials recorded from unmyelinated fibres. J Theor Biol 32:539_ 558.

Stein RB, Charles D, Davis L, Jhamandas J, Mannard A, Nichols TR (1975) Principles underlying new methods for chronic ncural rccording. Can J Neurol Sci 2:235-244.

Thomas PK (1966) The cellular response to nerve injury. 1. The cellular outgrowth from the distal stump of transected nerve. J Anat 100:287-303.

Thomas PK (1989) Invited review. Focal nerve injury: guidance factors during axonal regeneration. Muscle Nerve 12:796-802.

Toft PB, Fugleholm K, Schmalbruch H (1988) Axonal branching following crush lesions of peripheral nerves of rat. Muscle Nerve 11: 880-889.

Tomaselli KJ, Reichardt LF, Bixby JL (1986) Distinct molecular interactions mediate neuronal process outgrowth on non-neuronal cell surfaces and extracellular matrices. J Cell Biol 103:2659-2672.

Wang G-Y, Hirai K-I, Shimada H, Taji S, Zhong S-Z (1992) Behavior of axons, Schwann cells and pcrincurial cclls in nerve regeneration within transplanted nerve grafts: effects of anti-laminin and antifibronectin antisera. Brain Res 583:216-226.

Waxman SG, Black JA (1985) Membrane structures of vesicotubular complexes in developing axons in rat optic nerve: freeze-fracture evidence for sequential membrane assembly. Proc R Soc Lond [Biol] 225:357-363.

Weinberg HJ, Spencer PS (1978) The fate of Schwann cells isolated from axonal contact. J Neurocytol 7:555-569.

Weis J, Schröder M (1989) Differential effects of nerve, muscle, and fat tissue on regenerating nerve fibers in vivo. Muscle Nerve 12:723734.

Williams IR, Gilliatt RW (1977) Regeneration distal to a prolonged conduction block. J Neurol Sci 33:267-273.

Wood MR, DeBin J, Strichartz GR, Pfenninger KH (1992) Plasmalemmal insertion and modification of sodium channels at the nerve growth cone. J Neurosci 12:2948-2959.

Young JZ, Medawar PB (1940) Fibrin suture of peripheral nerves. Measurements of the rate of regeneration. Lancet $\mathrm{i}: 126-128$.

Zar JH (1984) Biostatistical analysis, 2d ed, pp 261-305. Englewood Cliffs, NJ: Prentice-Hall. 